\title{
Vertebrados Atropelados na BR-163, Entorno da Floresta Nacional do Tapajós, Pará: Influência dos Padrões Espaciais e Climáticos
}

\author{
Gabriela Batista ${ }^{1}$, Nilton Rascon 2 \& Clarissa Rosa ${ }^{3}$
}

\author{
Recebido em 20/10/2020 - Aceito em 31/03/2021 \\ ${ }^{1}$ Universidade Federal do Oeste do Pará/UFOPA, Brasil. <gabybatista08@hotmail.com> \\ ${ }^{2}$ Instituto Chico Mendes de Conservação da Biodiversidade/ICMBio, Brasil. < nilton.rascon@icmbio.org.br> \\ ${ }^{3}$ Instituto Nacional de Pesquisas da Amazônia/INPA, Brasil. <rosacla.eco@gmail.com>
}

\begin{abstract}
RESUMO - O atropelamento de fauna em rodovias é responsável pela mortalidade de inúmeras espécies, podendo causar declínio das populações animais. Este estudo avaliou a influência dos padrões espaciais e das variáveis climáticas dos grupos de vertebrados silvestres atropelados na BR-163, Pará. Realizamos o monitoramento em $201 \mathrm{~km}$ da rodovia, dos quais $151 \mathrm{~km}$ fazem limite com a Floresta Nacional do Tapajós. Identificamos os hotspots de atropelamento utilizando análise de Kernel e escolhemos os dados de temperatura e precipitação como variáveis climáticas. A paisagem do entorno da rodovia foi caracterizada e dividida em três recortes espaciais (Trechos 1, 2 e 3). Registramos 650 animais e a taxa de atropelamento de vertebrados foi de 0,08ind. $/ \mathrm{km} / \mathrm{dia}$. Entre as classes de animais, a maior taxa foi de anfíbios (0,03ind. $/ \mathrm{km} /$ dia), seguida de mamíferos $(0,02 \mathrm{ind} . /$ $\mathrm{km} /$ dia), aves $(0,02 \mathrm{ind} . / \mathrm{km} / \mathrm{dia})$ e répteis $(0,01 \mathrm{ind} . / \mathrm{km} / \mathrm{dia})$. Somente os mamíferos tiveram correlação significativa com as variáveis climáticas. As espécies com maior número de registro para mamíferos foram Didelphis sp. (29\%), Tamandua tetradactyla (17\%) e Cerdocyon thous (16\%); para aves foram Coragyps atratus (55\%) e Crotophaga ani (12\%); para anfíbios foi Rhinella marina (58\%) e para répteis foi Boa constrictor (36\%). Os hotspots dos vertebrados ocorreram, principalmente, nos Trechos 1 e 2, que são caracterizados pela presença de adensamentos urbanos e de plantações agrícolas. Os hotspots estão aparentemente relacionadas aos hábitos dos animais e paisagem do entorno, com alto índice de animais sinantrópicos sendo atropelados em trechos mais próximos a centros urbanos. Dessa forma, discutimos medidas de mitigação que podem garantir a conservação da fauna local (ex. redutores de velocidade, cercas e túneis).
\end{abstract}

Palavras-chave: Unidade de conservação; ecologia de estradas; impacto ambiental.

\section{Roadkill vertebrates on the BR-163, surrounding the Tapajós National Forest, Pará: influence of spatial and climatic patterns}

\begin{abstract}
The wildlife roadkill on highways is responsible for the mortality of innumerable species, which can cause a decline in animal populations. This study evaluated the influence of spatial patterns and climatic variables of wild vertebrate's road killed on the BR-163, Pará. We monitored $201 \mathrm{~km}$ of the highway, of which $151 \mathrm{~km}$ border the Tapajós National Forest. We identified the roadkill hotspots using Kernel analysis and we choose the temperature and precipitation data as climatic variables. The landscape close to the highway was characterized and divided into three spatial sections (Section 1, 2 and 3 ). We made 650 records, with the rate of roadkilled vertebrates being $0.08 \mathrm{ind} / \mathrm{km} /$ day. Between animal classes the highest rate was from amphibians $(0.03 \mathrm{ind} / \mathrm{km} /$ day $)$, followed by mammals $(0.02 \mathrm{ind} / \mathrm{km} /$ day $)$, birds $(0.02 \mathrm{ind} / \mathrm{km} / \mathrm{day})$ and reptiles $(0.01 \mathrm{ind} / \mathrm{km} / \mathrm{day})$. Only mammals had a significant correlation with climatic variables. The species with the highest number of records for mammals were Didelphis sp. (29\%), Tamandua tetradactyla (17\%) and Cerdocyon thous (16\%); for birds, were Coragyps atratus (55\%) and Crotophaga ani (12\%); for amphibians it was Rhinella marina (58\%); and for reptiles it was Boa constrictor $(36 \%)$. The vertebrate hotspots occurred mainly in sections 1 and 2 , which are characterized by the presence of urban agglomerations and crops. The hotspots are apparently related to the habits of animals and the surrounding landscape, with a high rate of synanthropic animals being killed in sections closer to urban centers. In this way, we discuss mitigation measures (eg speed reducers, fences and tunnels) can ensure the conservation of local fauna.
\end{abstract}

Keywords: Conservation unit; road ecology; environmental impact. 


\title{
Vertebrados atropellados en la BR-163, en los alrededores del Bosque Nacional Tapajós, Pará: influencia de los patrones espaciales y climáticos
}

\begin{abstract}
RESUMEN - El pisoteo de la fauna en las carreteras es responsable de la mortalidad de numerosas especies y puede causar la desestructuración de las poblaciones animales, especialmente en las unidades de conservación cortadas por las carreteras. Nuestro objetivo era caracterizar los animales atropellados en términos de estacionalidad y paisaje e identificar los puntos de atropello en la carretera BR-163, Pará. Hemos vigilado $201 \mathrm{~km}$ de la autopista, $151 \mathrm{~km}$ de los cuales bordean el Bosque Nacional del Tapajós (Flona). Realizamos 650 registros, la tasa total de atropello fue de 0,08 ind $/ \mathrm{km} /$ día, la tasa más alta fue la de los anfibios $(0,03 \mathrm{ind} / \mathrm{km} / \mathrm{día}-35 \%)$, seguida por la de los mamíferos $(0,02 \mathrm{ind} / \mathrm{km} /$ día-27\%), las aves $(0,02 \mathrm{ind} / \mathrm{km} / \mathrm{día}-21 \%)$ y los reptiles $(0,01 \mathrm{ind} / \mathrm{km} /$ día-17\%). Sólo los mamíferos tenían una correlación significativa con las variables climáticas $(p=0,01)$. La especie con el mayor número de registros de mamíferos fue Didelphis sp. (29\%), Tamandua tetradactyla (17\%) Cerdocyon thous (16\%); para las aves eran Coragyps atratus (55\%) y Crotophaga ani (12\%); para los anfibios era Rhinella marina (58\%); y los reptiles eran Boa constrictor (36\%). La mayor densidad de atropellos (hotspot) se produjo en los tramos 1 y 2 para mamíferos y reptiles; para anfibios y aves el hotspot se produjo en el tramo 1. La Flona do Tapajós, así como otras unidades de conservación, son áreas de preservación natural y refugios para la fauna. Con la caracterización de los animales atropellados y sus puntos de agregación se pueden aplicar medidas de mitigación más eficaces (por ejemplo, reductores de velocidad, vallas y túneles) que garanticen la conservación de la fauna local.
\end{abstract}

Palabras clave: Unidad de conservación; ecología vial; impacto ambiental.

\section{Introdução}

Rodovias causam a mortalidade direta dos animais por colisão com veículos, o que pode causar declínio de populações e, consequentemente, aumentar as chances de extinção para muitas espécies (Laurance, 2009; Winton et al., 2020). Ainda, as rodovias fragmentam, degradam $e$ criam barreias no habitat, alteram o microclima $e$ aumentam a poluição e desmatamento em seus entornos, afetando o comportamento $e$ distribuição dos animais, interferindo no fluxo gênico das espécies e facilitando a dispersão e proliferação de espécies exóticas (Forman \& Alexander, 1998; Keller \& Largiader, 2003; Jackson \& Fahrig, 2011).

O atropelamento de fauna está associado ao padrão de deslocamento dos animais na paisagem, principalmente pelo arranjo espacial dos recursos (e.g. abrigo e alimentação) na paisagem (Forman \& Alexander, 1998), e devido às variações sazonais que interferem na quantidade e qualidade desses recursos.

Os padrões de atropelamentos também podem sofrer influência das variáveis climáticas (Grilo et al., 2009; Rosa \& Bager, 2012). Padrões de agregação temporal e espacial (hotspots) de animais atropelados auxiliam a implantação de medidas de mitigação na rodovia que visem à manutenção das populações biológicas a longo prazo (Clevenger et al., 2003; Coelho et al., 2008; Rosa \& Bager, 2012).
Especificamente no Brasil, estudos avaliando hotspots de atropelamento têm sido mais comuns nos últimos anos, decorrentes da facilidade de uso do dispositivo GPS e softwares mais acessíveis para análises dos dados (Dornas et al., 2012; Gunson \& Teixeira, 2015). No entanto, a maioria dos estudos concentra-se na Mata Atlântica (ex. Coelho et al., 2008, Rosa et al., 2012, Abra et al., 2021) e no Cerrado (ex. Braz \& Franca, 2016; Medici et al., 2016; Maciel, 2019), com poucos estudos realizados no domínio amazônico (Cirino \& Freitas, 2018), Pantanal ou na Caatinga.

Atualmente, a rede viária do estado do Pará apresenta aproximadamente $11.754 \mathrm{~km}$ de rodovias (SETRAN, 2016), das quais $3.506 \mathrm{~km}$ são pavimentadas e $3.212 \mathrm{~km}$ não são pavimentadas. A BR-163, principal rodovia do Oeste do Pará, está inserida no complexo logístico do Arco Norte do país, possibilitando o avanço da fronteira agrícola, a expansão das atividades agropecuárias $e$ incorporação de novas áreas agrícolas para o interior da Amazônia, e tornou-se uma área com principais focos de desmatamento na Amazônia (Alencar, 2005; Fearnside \& Laurance, 2012; Ponte et al., 2015; Pastre, 2018).

O trecho Cuiabá-Santarém da BR-163 possui $1.780 \mathrm{~km}$ e foi construído durante o período da ditadura militar, em 1971, com o objetivo geopolítico de integração nacional. Esse trecho de rodovia atravessa uma das regiões mais importantes da Amazônia, do ponto de vista 
do potencial econômico, diversidade biológica, riquezas naturais e diversidade étnica e cultural (Fearnside, 2012). Devido a essa importância, após três anos do início das obras da rodovia BR-163, através do Decreto $n^{\circ} 73.684$ de fevereiro de 1974, foi criada a Floresta Nacional do Tapajós (Flona Tapajós), uma unidade de conservação federal de uso sustentável na região do Oeste do Pará e que tem a BR-163 como um dos seus limites.

Considerando a importância ambiental da região e a ausência de estudos que avaliem o impacto da BR-163 ao longo da Flona Tapajós, tivemos como objetivos deste estudo: (1) identificar e quantificar a fauna atropelada; (2) identificar os trechos de maior atropelamento; (3) avaliar a relação da temperatura e precipitação com a fauna atropelada na BR-163 e (4) discutir estratégias de medidas de mitigação para mortalidade de vertebrados.

\section{Material e Métodos}

\section{Área de estudo}

Nosso estudo foi realizado em um trecho de $201 \mathrm{~km}$ da rodovia BR-163, Oeste do Pará. O trecho inicia no km 10 (base Polícia Rodoviária Federal de Santarém, PA) até o km 211 (limite final da Flona Tapajós). A via é pavimentada e contém duas faixas de rolamento, com aproximadamente 11 metros de largura, considerando os acostamentos. Esse trecho percorre os municípios de Santarém, Mojuí dos Campos e Belterra, incluindo os $151 \mathrm{~km}$ finais que ocorrem ao longo dos limites da Flona Tapajós (Figura 1). A Flona Tapajós possui atualmente uma área de 527.319 hectares que envolve os municípios de Belterra, Placas, Aveiro e Rurópolis. As suas principais vias de acesso são a rodovia BR-163 (limite leste) e o rio Tapajós (limite oeste) (ICMBio, 2019).

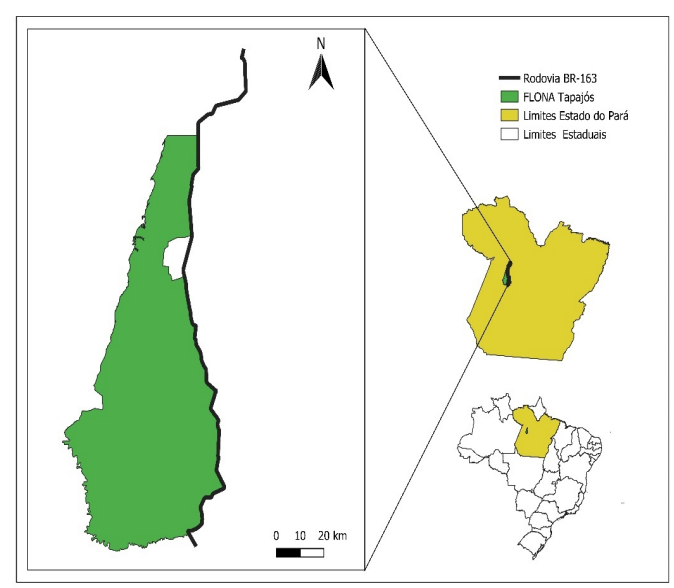

Figura 1 - Trecho de 201km monitorado na BR-163 e limites da Floresta Nacional do Tapajós.
O clima da região é classificado como Ami no sistema Köppen, ou seja, tropical úmido com variação térmica anual inferior a $5^{\circ} \mathrm{C}$, e a temperatura média anual é de $25,5^{\circ} \mathrm{C}$, com uma precipitação média anual de $1.820 \mathrm{~mm}$ (IBAMA, 2004). A região apresenta um período sazonal chuvoso com início de dezembro até maio, categorizando o inverno, e outro menos chuvoso, período de verão, corresponde geralmente ao período de junho a novembro (Moraes et al., 2005). A vegetação nativa dominante na região é a Floresta Ombrófila Densa, que se caracteriza pela dominância de árvores de grande porte sob regime climático de temperaturas elevadas $e$ intensas precipitações distribuídas ao longo do ano (Pinho et al., 2004). Além da vegetação nativa, a Flona Tapajós também apresenta pequenas áreas agroflorestais e inúmeras espécies da fauna amazônica, entre elas, 55 espécies são ameaçadas de extinção, em nível nacional, e 24 espécies em nível estadual (ICMBio, 2019).

\section{Coleta de dados}

Realizamos o monitoramento de fauna atropelada durante dois anos (junho de 2018 até março de 2020). O monitoramento obedeceu a uma periodicidade de 15 dias, totalizando 39 expedições de campo e $7.839 \mathrm{~km}$ percorridos. Os monitoramentos duraram em média oito horas, tempo necessário para percorrer todo o trajeto com um carro oficial do ICMBio, a uma velocidade média de $50 \mathrm{~km} / \mathrm{h}$, com motorista e um observador, contabilizando carcaças nas duas faixas de rolamento. Os animais registrados foram aqueles indivíduos que estavam entre as faixas de rolamento $e$ acostamento. Não foram amostrados animais fora da faixa de domínio da rodovia. Para cada animal atropelado, foram registrados os seguintes dados: classe, nome, quilometragem, data/hora, coordenadas geográficas e registros fotográficos, removemos as carcaças dos animais para evitar posteriores recontagens (Hegel et al., 2012). Os registros fotográficos foram utilizados para validar posteriormente alguns animais $e$, com isso, pudemos chegar nos menores níveis taxonômicos possíveis.

A identificação dos animais foi realizada por meio de comparações a bancos de dados, uso de guias de campo, consultas a acervos e coleções científicas de referência e foram identificados por especialistas de instituições de pesquisa 
científica. Sempre que possivel, os animais atropelados encontrados foram caracterizados quanto ao status de conservação segundo a Lista das Espécies Ameaçadas de Extinção no Estado do Pará (Resolução COEMA n ${ }^{\circ} 54$ de 24/10/2007) e o Livro Vermelho da fauna brasileira ameaçada de extinção - ICMBio (2018) para Brasil e IUCN (2020) em nível mundial. Quando encontradas carcaças em boas condições, elas foram encaminhadas para a Universidade Federal do Oeste do Pará, para fins de estudos anatômicos didáticos, com autorização concedida pelo Sistema de Autorização e Informação em Biodiversidade (Sisbio) no 64.149.

Tivemos acesso a dados de precipitação, temperaturas máxima e mínima durante nosso período de amostragem no banco de dados do Instituto Nacional de Meteorologia do Brasil (INMET, portal.inmet.gov.br), estação meteorológica de Belterra (estação OMM: 82246). As séries históricas dessas estações foram usadas para contabilizarmos o volume médio mensal de precipitação acumulada $(\mathrm{mm})$ e a temperatura máxima e mínima média mensal da área de estudo para os mesmos meses do registro do atropelamento.
O trecho estudado da BR-163 não possui informações disponíveis sobre tráfego de veículos, mas é visível que há uma maior circulação de pessoas e de veículos nos primeiros $50 \mathrm{~km}$ da rodovia, onde há concentração de centros urbanos, enquanto o trecho que corta a Flona Tapajós possui somente residências e pequenos assentamentos humanos isolados ao longo da rodovia, sem concentração de áreas urbanas. Sendo assim, para melhor caracterizar e entender os atropelamentos, dividimos o trecho estudados em três recortes espaciais de análise (Trechos 1, 2 e 3), segundo a paisagem predominante no entorno da rodovia (T1: com 50km de extensão; T2: com 67km de extensão e T3: com total de $84 \mathrm{~km}$ ). Para isso, utilizamos o mapa de uso e cobertura do solo com bases cartográficas e imagens TM/Landsat resolução espacial 30 metros, no período de 2014 do projeto TerraClass. Geramos um mapa no programa QGIS, com buffer de $10 \mathrm{~km}$ no entorno da rodovia, dividido em sete classes de uso de cobertura da terra: agricultura anual, área urbana, desmatamento, floresta, mosaico de ocupação, pastagem e vegetação secundária. Isso resultou em três trechos com diferentes proporções de área urbana e vegetação nativa (Figura 2).

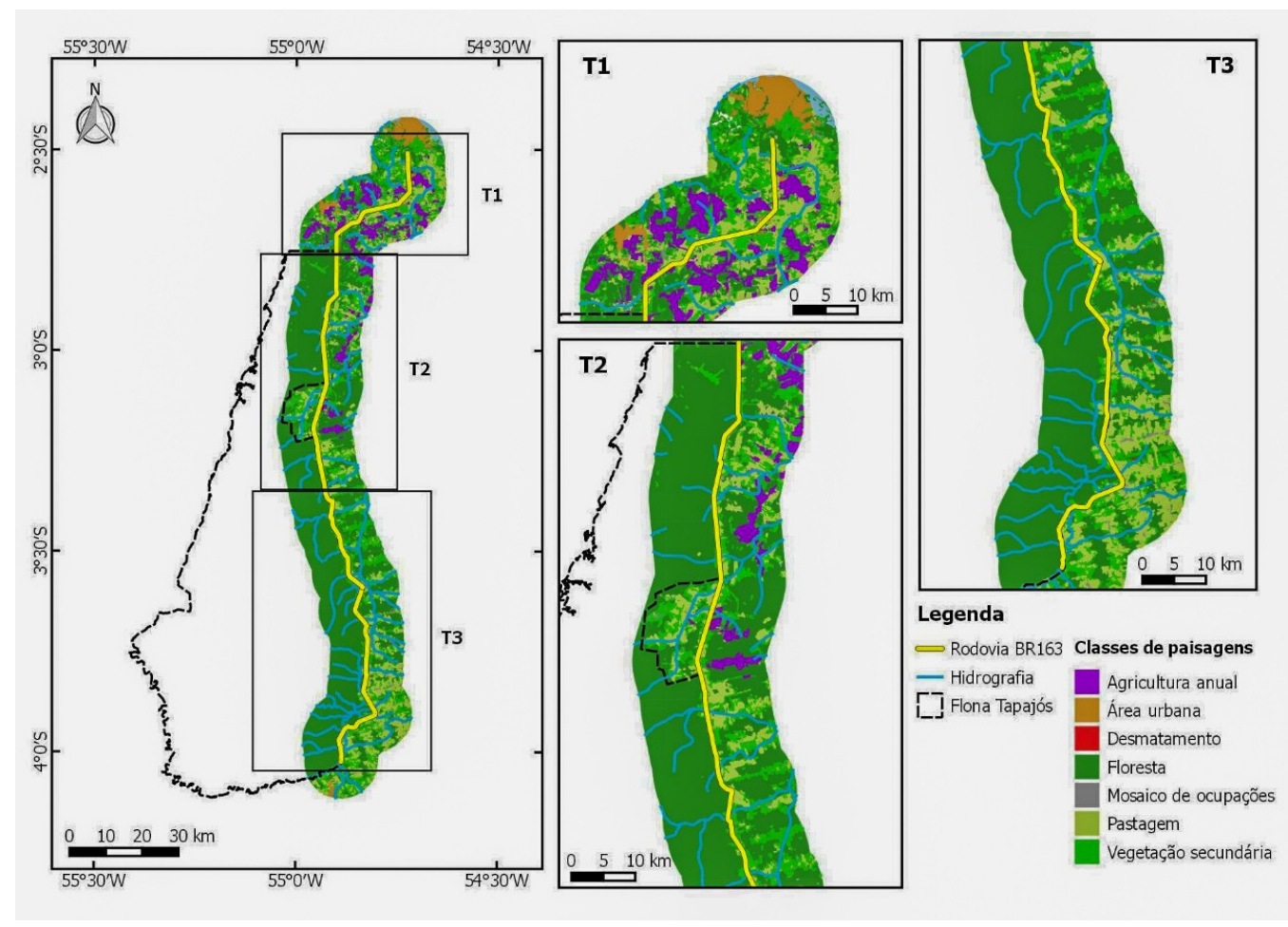

Figura 2 - Mapa de representação dos trechos - T1, T2 e T3 (Uso e cobertura do solo no entorno da rodovia BR-163).

Fonte: $\quad$ Base de dados Projeto TerraClass/INPE/Embrapa.

Elaboração: Joelson Lima. 
O Trecho 1, entre o $\mathrm{km} 10$ e $\mathrm{km} \mathrm{50,}$ percorre os principais acessos aos municípios de Santarém, Mojui dos Campos e Belterra. Esse é o trecho com maiores atividades antrópicas $e$ vegetação secundária, havendo predominância de manchas urbanas decorrentes da concentração populacional e maior fluxo de veículos. O trecho apresenta infraestrutura diferenciada da área rural, com casas, equipamentos públicos e intensa produção agrícola de grãos (Figuras $3 \mathrm{~A}, \mathrm{~B}$ ).

O Trecho 2, entre os $\mathrm{km} 50$ e $\mathrm{km} \mathrm{117,}$ coincide com o início da Flona Tapajós. Ao lado direito (sentido Santarém-Cuiabá), no entorno da BR-163, ocorre a presença de florestas preservadas e refúgios vegetacionais (até $\mathrm{km} 86$ da Flona Tapajós) com relevo local, pouco acidentado (Figura 3C). Posteriormente, ocorre uma área com agricultura intensa, localizada nas comunidades São Jorge, Santa Clara, Nossa Senhora do Nazaré e Nova Vista (área que foi desvinculada da Flona Tapajós em 2012), com sistemas agroflorestais (SAFs), pastagens e manejo florestal. Ao lado esquerdo da rodovia, oposto à Flona, ocorre a presença de área com vegetação secundária, $e$ grande parte da área é agricultura de grãos (milho e soja) e pastagem (Figura 3D). Possui também projetos de assentamentos da reforma agrária, a maioria deles são Projetos de Assentamentos Extrativistas (PAE) e Projetos de Assentamentos de Desenvolvimento Sustentável (PDS).

OTrecho3, entre okm 117 e km211, percorre o município de Placas até início de Rurópolis. No lado direito da rodovia, o entorno da Flona Tapajós, ocorre a predominância de floresta nativa e, próximo à pista da rodovia, manchas urbanas decorrentes da concentração populacional do Projeto Integrado de Colonização (PIC), a zona conflitante do plano de manejo da Flona Tapajós. O Trecho 3 detém o maior número de áreas enquadradas, com áreas em regióes de topo de morro e com ocorrência de nascentes de cabeceira (Figura 3E). No lado esquerdo da rodovia, ocorre a presença de manchas de vegetação secundária, área de pastagem em processo produtivo com predomínio de vegetação herbácea e cobertura de gramíneas, pasto com solo exposto, áreas com pelo menos $50 \%$ de solo exposto com alguma atividade agropastoril e presença de Projetos de Assentamentos Extrativistas (PAE) e Projetos de Assentamentos de Desenvolvimento Sustentável (PDS) (Figura 3F).

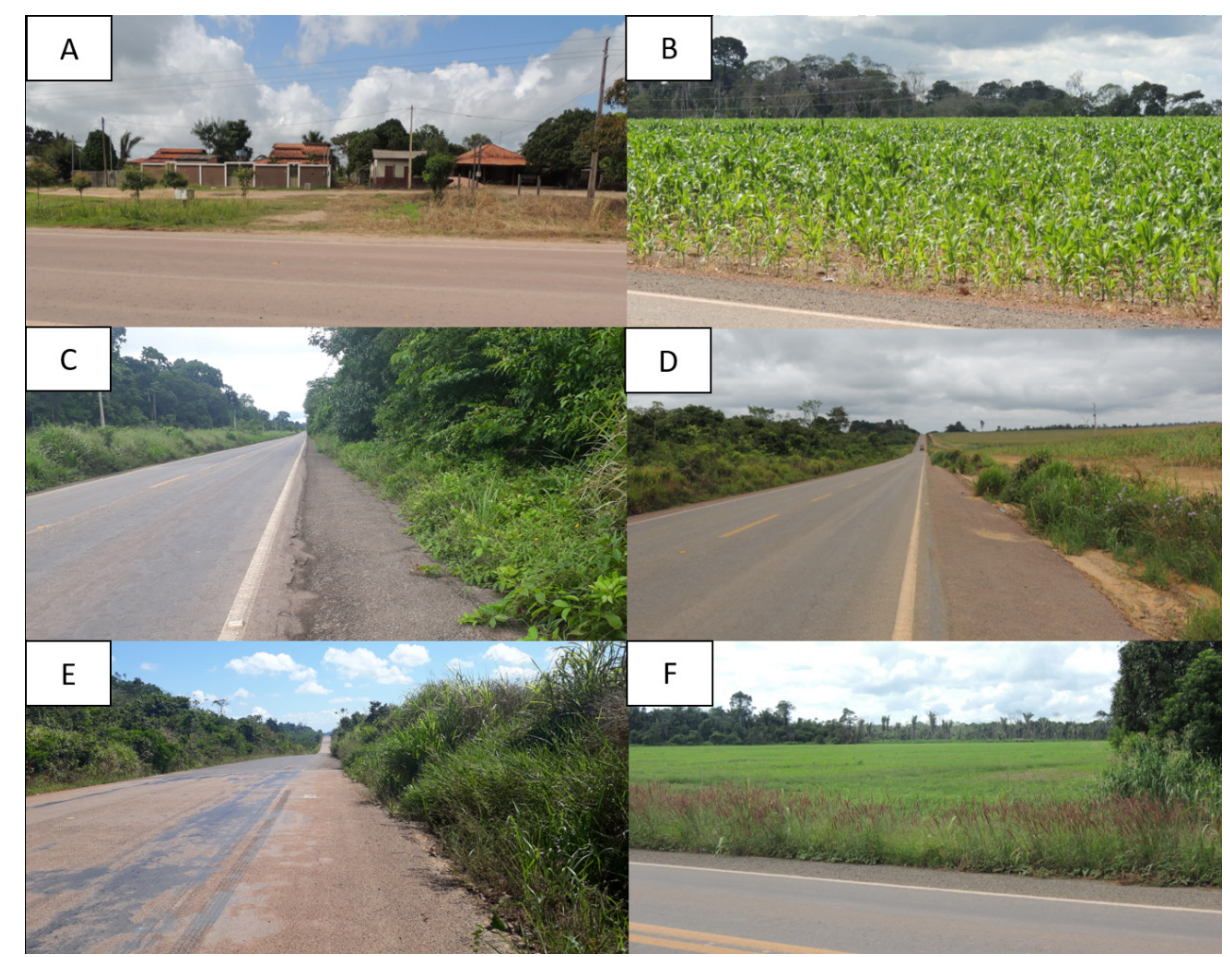

Figura 3 - No Trecho 1, áreas com concentração urbana (A) e produção agrícola de grãos (B). No Trecho 2, floresta preservada $(C)$ e áreas de produção agrícola de grãos (D). No Trecho 3, áreas de floresta nativa (E) e área de pastagem (F). 


\section{Análise de dados}

A taxa de atropelamento observada total e por trechos foi calculada com base nos indivíduos atropelados/quilometragem da rodovia/dias de coleta (indivíduo $/ \mathrm{km} / \mathrm{dia}$ ) sugerido por Bager \& Rosa (2010), até o mês de março 2020. Para taxa de atropelamento mensal, foram considerados os indivíduos $/ \mathrm{km} / \mathrm{dia}$ em 18 meses de monitoramento. Justifica-se essa metodologia pelas condições sanitárias da COVID-19 em 2020 , restringindo coletas de campos, por isso não fechamos duas estações sazonais da região bem definidas para correlação, no entanto, usamos taxas de atropelamento mensais para correlacionar com as variáveis climáticas.

Para verificar se existia relação entre as variáveis climáticas (precipitação, temperatura máxima e mínima) com as taxas de atropelamento mensal de mamíferos, aves, répteis e anfíbios, utilizamos o teste de correlação de Pearson (r) para dados normais e teste de correlação de Sperman (rs) para dados não normais. A normalidade dos dados foi realizada pelo teste Shapiro-Wilk, e todos os testes foram realizados no programa BioEstat 5.3(Ayres et al., 2007).

As análises de hotspots avaliam a densidade de pontos em uma determinada área e medem a extensão da interação de evento dos pontos para entender os padrões espaciais (Baddeley, 2010). Para representar os hotspots, são utilizadas diferentes técnicas, incluindo as seguintes: mapas temáticos de áreas geográficas, elipses espaciais, mapas temáticos em formato de grade e estimativa de densidade de kernel (Chainey et al., 2008). Sendo assim, na análise de hotspots, realizamos o mapeamento da densidade de atropelamento por meio da estimativa da densidade de Kernel em rede com bandwidth 150. Segundo Wenhao \& Tinghua (2014), quando maior a bandwidth, mais suave será a distribuição de densidade e mais preciso será os "pontos quentes". Cabe destacar que se trata de uma técnica de interpolação exploratória, esta ferramenta realiza uma contagem de todos os pontos dentro de uma região de influência, ponderando-os pela distância de cada um à localização de interesse (Câmara \& Carvalho,2004).

Os dados de densidade foram categorizados (5 faixas) através do método quebras naturais (Jenks), esse método agrupa os valores similares e maximiza as diferenças entre as classes (ESRI, 2016). E foram executadas no software QGIS versão 3.16 (https://qgis.org/pt_ $\mathrm{BR} /$ site/). As análises de Kernel em rede foram realizadas no software SANET, Spatial Analysis along Network - Standalone (http://sanet.csis.utokyo.ac.jp/). Em seguida, foi gerado um arquivo vetorial no QGIS (nuvem de pontos coletados), contendo todas as informações coletadas dos atropelamentos na rodovia. $\mathrm{O}$ arquivo foi utilizado como base para geração dos mapas de análise espacial e densidade específicos por classe (mamíferos, aves, répteis e anfíbios).

\section{Resultados}

\section{Caracterização da fauna atropelada $e$ relação com variáveis climáticas}

Registramos 650 espécimes de animais silvestres atropelados, classificadas em quatro classes distintas: anfíbios (35\%, $\mathrm{N}=225)$, mamíferos $(27 \%, \mathrm{~N}=176)$, aves $(21 \%, \mathrm{~N}=134)$ e répteis $(17 \%, \mathrm{~N}=110)$. Registramos ainda $1 \%(\mathrm{~N}=5)$ de carcaças que não puderam ser identificadas devido ao grau de decomposição. As espécies Dasypus spp. $(\mathrm{N}=11)$, Eira barbara $(\mathrm{N}=5)$ e Nasua nasua $(\mathrm{N}=14)$ tiveram registro de atropelamento somente nos Trechos 2 e 3 , que ocorre no entorno da Flona Tapajós. Registramos somente uma espécie ameaçada de extinção, Myrmecophaga tridactyla $(\mathrm{N}=1)$, atropelada no Trecho 2 que se encontra vulnerável a nível estadual, nacional e global, além do Mico argentatus ( $\mathrm{N}=7$ ) que é endêmico do estado do Pará, único primata registrado atropelado neste estudo nos Trechos 1 e 2 .

Quanto à diversidade da fauna atropelada, os indivíduos foram identificados, quando possível, no menor nível taxonômico. Houve registro total de 19 ordens, 38 famílias, 57 gêneros e 65 espécies de vertebrados silvestres (Tabela 1). 
Tabela 1 - Número (total) e frequência (\%) de vertebrados silvestres atropelados ao longo do trecho da rodovia BR-163, Pará- Brasil, de 2018 a 2020, incluindo categorias de ameaça no estado (COEMA, 2007), nacional (Níveis ICMBio, 2018) e mundial (IUCN, 2020).

\begin{tabular}{|c|c|c|c|c|c|c|}
\hline \multirow[b]{2}{*}{ Grupos } & \multirow[b]{2}{*}{ Nome popular } & \multirow{2}{*}{\begin{tabular}{|c|} 
Total \\
$\mathbf{N}$ \\
\end{tabular}} & \multirow{2}{*}{\begin{tabular}{|c|} 
Frequência \\
$\%$ C*
\end{tabular}} & \multicolumn{3}{|c|}{ Status de conservação } \\
\hline & & & & $\begin{array}{c}\text { IUCN } \\
2020\end{array}$ & $\begin{array}{c}\text { ICMBio } \\
2018\end{array}$ & $\begin{array}{c}\text { COEMA } \\
2007\end{array}$ \\
\hline \multicolumn{7}{|l|}{ MAMÍFEROS } \\
\hline \multicolumn{7}{|l|}{ Carnivora } \\
\hline \multicolumn{7}{|l|}{ Canidae } \\
\hline Cerdocyon thous & Cachorro do mato & 28 & 15.9 & LC & $\mathrm{N} / \mathrm{C}$ & $\mathrm{N} / \mathrm{C}$ \\
\hline \multicolumn{7}{|l|}{ Felidae } \\
\hline Leopardus pardalis & Jaguatirica & 1 & 0.6 & LC & $\mathrm{N} / \mathrm{C}$ & $\mathrm{N} / \mathrm{C}$ \\
\hline \multicolumn{7}{|l|}{ Mustelidae } \\
\hline Eira barbara & Irara & 5 & 2.8 & LC & $\mathrm{N} / \mathrm{C}$ & $\mathrm{N} / \mathrm{C}$ \\
\hline \multicolumn{7}{|l|}{ Procyonidae } \\
\hline Nasua nasua & Quati & 14 & 8.0 & LC & $\mathrm{N} / \mathrm{C}$ & $\mathrm{N} / \mathrm{C}$ \\
\hline Potos flavus & Japurá & 2 & 1.1 & LC & $\mathrm{N} / \mathrm{C}$ & $\mathrm{N} / \mathrm{C}$ \\
\hline \multicolumn{7}{|l|}{ Chiroptera } \\
\hline \multicolumn{7}{|l|}{ desconhecido } \\
\hline \multicolumn{7}{|l|}{ Cingulata } \\
\hline \multicolumn{7}{|l|}{ Dasypodidae } \\
\hline Dasypus novemcinctus & Tatu galinha & 6 & 3.4 & LC & $\mathrm{N} / \mathrm{C}$ & $\mathrm{N} / \mathrm{C}$ \\
\hline Dasypus sp. & Tatu & 5 & 2.8 & & & \\
\hline Cabassous sp. & Tatu & 1 & 0.6 & & & \\
\hline \multicolumn{7}{|l|}{ Didelphimorphia } \\
\hline \multicolumn{7}{|l|}{ Didelphidae } \\
\hline Didelphis marsupialis & Mucura & 3 & 1.7 & & & \\
\hline Marmosa murina & Mucurinha & 1 & 0.6 & LC & $\mathrm{N} / \mathrm{C}$ & $\mathrm{N} / \mathrm{C}$ \\
\hline Didelphis sp. & Mucura & 48 & 27.3 & & & \\
\hline \multicolumn{7}{|l|}{ Pilosa } \\
\hline \multicolumn{7}{|l|}{ Myrmecophagidae } \\
\hline Tamandua tetradactyla & Tamanduá mirim & 31 & 17.6 & LC & $\mathrm{N} / \mathrm{C}$ & $\mathrm{N} / \mathrm{C}$ \\
\hline Myrmecophaga tridactyla & Tamanduá bandeira & 1 & 0.6 & VU & VU & VU \\
\hline desconhecido & & 5 & 2.8 & & & \\
\hline \multicolumn{7}{|l|}{ Primatas } \\
\hline \multicolumn{7}{|l|}{ Callitrichidae } \\
\hline Mico argentatus & Sagui branco & 7 & 4.0 & LC & $\mathrm{N} / \mathrm{C}$ & $\mathrm{N} / \mathrm{C}$ \\
\hline \multicolumn{7}{|l|}{ Rodentia } \\
\hline \multicolumn{7}{|l|}{ Erethizontidae } \\
\hline Coendou sp. & Porco espinho & 5 & 2.8 & & & \\
\hline desconhecido & & 2 & 1.1 & & & \\
\hline \multicolumn{7}{|l|}{ Caviidae } \\
\hline Hydrochoerus hydrochaeris & Capivara & 3 & 1.7 & LC & $\mathrm{N} / \mathrm{C}$ & $\mathrm{N} / \mathrm{C}$ \\
\hline desconhecido & & 4 & 2.3 & & & \\
\hline
\end{tabular}




\begin{tabular}{|c|c|c|c|c|c|c|}
\hline \multirow[b]{2}{*}{ Grupos } & \multirow[b]{2}{*}{ Nome popular } & \multirow{2}{*}{$\begin{array}{c}\text { Total } \\
\mathbf{N}\end{array}$} & \multirow{2}{*}{$\begin{array}{c}\text { Frequência } \\
\mathrm{CC}^{*}\end{array}$} & \multicolumn{3}{|c|}{ Status de conservação } \\
\hline & & & & $\begin{array}{l}\text { IUCN } \\
2020\end{array}$ & $\begin{array}{c}\text { ICMBio } \\
2018\end{array}$ & $\begin{array}{c}\text { COEMA } \\
2007\end{array}$ \\
\hline \multicolumn{7}{|l|}{ AVES } \\
\hline \multicolumn{7}{|l|}{ Accipitriformes } \\
\hline Desconhecido & & 3 & 2.2 & & & \\
\hline \multicolumn{7}{|l|}{ Apodiformes } \\
\hline \multicolumn{7}{|l|}{ Trochilidae } \\
\hline Campylopterus largipennis & Asa-de-sabre-cinza & 1 & 0.7 & LC & $\mathrm{N} / \mathrm{C}$ & $\mathrm{N} / \mathrm{C}$ \\
\hline \multicolumn{7}{|l|}{ Cathartiformes } \\
\hline \multicolumn{7}{|l|}{ Cathartidae } \\
\hline Coragyps atratus & Urubu & 74 & 55.2 & LC & $\mathrm{N} / \mathrm{C}$ & $\mathrm{N} / \mathrm{C}$ \\
\hline \multicolumn{7}{|l|}{ Columbiformes } \\
\hline \multicolumn{7}{|l|}{ Columbidae } \\
\hline desconhecido & & 1 & 0.7 & & & \\
\hline Columbina passerina & Rolinha & 1 & 0.7 & LC & $\mathrm{N} / \mathrm{C}$ & $\mathrm{N} / \mathrm{C}$ \\
\hline Zenaida auriculata & Avoante & 1 & 0.7 & LC & $\mathrm{N} / \mathrm{C}$ & $\mathrm{N} / \mathrm{C}$ \\
\hline \multicolumn{7}{|l|}{ Cuculiformes } \\
\hline \multicolumn{7}{|l|}{ Cuculidae } \\
\hline Crotophaga ani & Anu preto & 14 & 10.4 & LC & $\mathrm{N} / \mathrm{C}$ & $\mathrm{N} / \mathrm{C}$ \\
\hline Piaya cayana & Alma-de-gato & 1 & 0.7 & LC & $\mathrm{N} / \mathrm{C}$ & $\mathrm{N} / \mathrm{C}$ \\
\hline \multicolumn{7}{|l|}{ Passeriformes } \\
\hline \multicolumn{7}{|l|}{ Dendrocolaptidae } \\
\hline Xiphorhynchus sp. & & 1 & 0.7 & & & \\
\hline Dendrocolaptes sp. & & 1 & 0.7 & & & \\
\hline \multicolumn{7}{|l|}{ Thamnophilidae } \\
\hline Drymophila sp. & & 1 & 0.7 & & & \\
\hline \multicolumn{7}{|l|}{ Thraupidae } \\
\hline Tangara episcopus & Pipira & 4 & 3.0 & LC & $\mathrm{N} / \mathrm{C}$ & $\mathrm{N} / \mathrm{C}$ \\
\hline desconhecido & & 1 & 0.7 & & & \\
\hline \multicolumn{7}{|l|}{ Tyrannidae } \\
\hline Phyllomyias sp. & & 1 & 0.7 & & & \\
\hline Tyrannus sp. & & 1 & 0.7 & & & \\
\hline \multicolumn{7}{|l|}{ Emberizidae } \\
\hline Sporophila sp. & & 1 & 0.7 & & & \\
\hline \multicolumn{7}{|l|}{ Troglodytidae } \\
\hline desconhecido & & 1 & 0.7 & & & \\
\hline Desconhecido & & 19 & 14.2 & & & \\
\hline \multicolumn{7}{|l|}{ Pelecaniformes } \\
\hline Ardea alba & Garça & 1 & 0.7 & LC & $\mathrm{N} / \mathrm{C}$ & $\mathrm{N} / \mathrm{C}$ \\
\hline \multicolumn{7}{|l|}{ Strigiformes } \\
\hline Strigidae & & & & & & \\
\hline Athene cunicularia & Coruja buraqueira & 1 & 1.2 & LC & $\mathrm{N} / \mathrm{C}$ & $\mathrm{N} / \mathrm{C}$ \\
\hline desconhecido & & 5 & 5.8 & & & \\
\hline
\end{tabular}




\begin{tabular}{|c|c|c|c|c|c|c|}
\hline \multirow[b]{2}{*}{ Grupos } & \multirow[b]{2}{*}{ Nome popular } & \multirow{2}{*}{$\begin{array}{c}\text { Total } \\
\mathbf{N}\end{array}$} & \multirow{2}{*}{$\begin{array}{c}\text { Frequência } \\
\% C^{*}\end{array}$} & \multicolumn{3}{|c|}{ Status de conservação } \\
\hline & & & & $\begin{array}{l}\text { IUCN } \\
2020\end{array}$ & $\begin{array}{c}\text { ICMBio } \\
2018\end{array}$ & $\begin{array}{c}\text { COEMA } \\
2007\end{array}$ \\
\hline \multicolumn{7}{|l|}{ ANFíBIOS } \\
\hline \multicolumn{7}{|l|}{ Anura } \\
\hline \multicolumn{7}{|l|}{ Bufonidae } \\
\hline Rhinella marina & sapo cururu & 131 & 58.2 & LC & $\mathrm{N} / \mathrm{C}$ & $\mathrm{N} / \mathrm{C}$ \\
\hline Rhinella marjor & sapo & 1 & 0.4 & LC & $\mathrm{N} / \mathrm{C}$ & $\mathrm{N} / \mathrm{C}$ \\
\hline desconhecido & & 11 & 4.9 & & & \\
\hline \multicolumn{7}{|l|}{ Hylidae } \\
\hline Trachycephalus typhonius & perereca & 3 & 1.3 & LC & $\mathrm{N} / \mathrm{C}$ & $\mathrm{N} / \mathrm{C}$ \\
\hline desconhecido & & 74 & 32.9 & & & \\
\hline \multicolumn{7}{|l|}{ Leptodactylidae } \\
\hline desconhecido & & 1 & 0.4 & & & \\
\hline Leptodactylus macrosternum & Rã-touro & 1 & 0.4 & LC & $\mathrm{N} / \mathrm{C}$ & $\mathrm{N} / \mathrm{C}$ \\
\hline Leptodactylus pentadactylus & Rã & 1 & 0.4 & LC & $\mathrm{N} / \mathrm{C}$ & $\mathrm{N} / \mathrm{C}$ \\
\hline Leptodate sp. & & 1 & 0.4 & & & \\
\hline Leptodactylus sp & & 1 & 0.4 & & & \\
\hline \multicolumn{7}{|l|}{ RÉPTEIS } \\
\hline \multicolumn{7}{|l|}{ Crocodilianos } \\
\hline Alligatoridae & & 1 & 0.91 & & & \\
\hline \multicolumn{7}{|l|}{ Squamata } \\
\hline \multicolumn{7}{|l|}{ Amphisbaenidae } \\
\hline Amphisbaena fuliginosa & cobra duas cabeças & 8 & 7.3 & LC & $\mathrm{N} / \mathrm{C}$ & $\mathrm{N} / \mathrm{C}$ \\
\hline \multicolumn{7}{|l|}{ Boidae } \\
\hline Boa constrictor & jiboia & 39 & 35.5 & $\mathrm{~N} / \mathrm{C}$ & $\mathrm{N} / \mathrm{C}$ & $\mathrm{N} / \mathrm{C}$ \\
\hline Epicrates cenchria & jiboia arco iris & 4 & 3.6 & $\mathrm{~N} / \mathrm{C}$ & $\mathrm{N} / \mathrm{C}$ & $\mathrm{N} / \mathrm{C}$ \\
\hline Corallus hortulanus & suaçubóia & 1 & 0.9 & LC & $\mathrm{N} / \mathrm{C}$ & $\mathrm{N} / \mathrm{C}$ \\
\hline \multicolumn{7}{|l|}{ Aniliidae } \\
\hline Anilius scytale & & 1 & 0.9 & LC & $\mathrm{N} / \mathrm{C}$ & $\mathrm{N} / \mathrm{C}$ \\
\hline \multicolumn{7}{|l|}{ Colubridae } \\
\hline desconhecido & & 2 & 1.8 & & & \\
\hline Chironius carinatus & acutimbóia & 1 & 0.9 & $\mathrm{~N} / \mathrm{C}$ & $\mathrm{N} / \mathrm{C}$ & $\mathrm{N} / \mathrm{C}$ \\
\hline Chironius multiventris & Cobra-cipó & 1 & 0.9 & LC & $\mathrm{N} / \mathrm{C}$ & $\mathrm{N} / \mathrm{C}$ \\
\hline Chironius scurrulus & Cobra-cipó & 2 & 1.8 & LC & $\mathrm{N} / \mathrm{C}$ & $\mathrm{N} / \mathrm{C}$ \\
\hline Drepanoides anomalus & $\begin{array}{l}\text { cobra de colarinho } \\
\text { preto }\end{array}$ & 1 & 0.9 & LC & $\mathrm{N} / \mathrm{C}$ & $\mathrm{N} / \mathrm{C}$ \\
\hline Drymarchon corais & $\begin{array}{l}\text { cobra de cauda } \\
\text { amarela }\end{array}$ & 2 & 1.8 & LC & $\mathrm{N} / \mathrm{C}$ & $\mathrm{N} / \mathrm{C}$ \\
\hline Helicops sp. & cobra-d'água & 1 & 0.9 & & & \\
\hline Leptophis ahaetulla & cobra papagaio & 1 & 0.9 & LC & $\mathrm{N} / \mathrm{C}$ & $\mathrm{N} / \mathrm{C}$ \\
\hline Mastigodryas boddaerti & biru-listrada & 2 & 1.8 & LC & $\mathrm{N} / \mathrm{C}$ & $\mathrm{N} / \mathrm{C}$ \\
\hline Oxybelis fulgidus & cobra verde & 2 & 1.8 & LC & $\mathrm{N} / \mathrm{C}$ & $\mathrm{N} / \mathrm{C}$ \\
\hline Oxyrhopus petolarius & falsa coral & 3 & 2.7 & LC & $\mathrm{N} / \mathrm{C}$ & $\mathrm{N} / \mathrm{C}$ \\
\hline Philodryas olfersii & cobra-cipó-verde & 5 & 4.5 & LC & $\mathrm{N} / \mathrm{C}$ & $\mathrm{N} / \mathrm{C}$ \\
\hline Chlorosoma viridissima & corredor verde & 1 & 0.9 & $\mathrm{~N} / \mathrm{C}$ & $\mathrm{N} / \mathrm{C}$ & $\mathrm{N} / \mathrm{C}$ \\
\hline Pseudoboa sp. & & 2 & 1.8 & & & \\
\hline
\end{tabular}




\begin{tabular}{|c|c|c|c|c|c|c|}
\hline \multirow[b]{2}{*}{ Grupos } & \multirow[b]{2}{*}{ Nome popular } & \multirow{2}{*}{\begin{tabular}{|c|} 
Total \\
$\mathbf{N}$ \\
\end{tabular}} & \multirow{2}{*}{\begin{tabular}{|c|} 
Frequência \\
$\% C^{*}$
\end{tabular}} & \multicolumn{3}{|c|}{ Status de conservação } \\
\hline & & & & $\begin{array}{c}\text { IUCN } \\
2020\end{array}$ & $\begin{array}{c}\text { ICMBio } \\
2018\end{array}$ & $\begin{array}{c}\text { COEMA } \\
2007\end{array}$ \\
\hline Rhinobothry lentiginosum & falsa-coral & 1 & 0.9 & $\mathrm{~N} / \mathrm{C}$ & $\mathrm{N} / \mathrm{C}$ & $\mathrm{N} / \mathrm{C}$ \\
\hline Spilotes pullatus & Caninana & 3 & 2.7 & LC & $\mathrm{N} / \mathrm{C}$ & $\mathrm{N} / \mathrm{C}$ \\
\hline \multicolumn{7}{|l|}{ Dipsadidae } \\
\hline desconhecido & & 1 & 0.9 & & & \\
\hline \multicolumn{7}{|l|}{ Elapidae } \\
\hline Micrurus lemniscatus & Cobra-coral & 1 & 0.9 & LC & $\mathrm{N} / \mathrm{C}$ & $\mathrm{N} / \mathrm{C}$ \\
\hline Teiidae & & & 0.0 & & & \\
\hline Ameiva ameiva & calango-verde & 4 & 3.6 & LC & $\mathrm{N} / \mathrm{C}$ & $\mathrm{N} / \mathrm{C}$ \\
\hline \multicolumn{7}{|l|}{ Iguanidae } \\
\hline desconhecido & & 2 & 1.8 & & & \\
\hline Iguana sp. & & 1 & 0.9 & & & \\
\hline Iguana iguana & iguana & 2 & 1.8 & LC & $\mathrm{N} / \mathrm{C}$ & $\mathrm{N} / \mathrm{C}$ \\
\hline \multicolumn{7}{|l|}{ Viperidae } \\
\hline Bothrops atrox & jararaca & 2 & 1.8 & $\mathrm{~N} / \mathrm{C}$ & $\mathrm{N} / \mathrm{C}$ & $\mathrm{N} / \mathrm{C}$ \\
\hline Lachesis muta & pico de jaca & 2 & 1.8 & $\mathrm{~N} / \mathrm{C}$ & $\mathrm{N} / \mathrm{C}$ & $\mathrm{N} / \mathrm{C}$ \\
\hline desconhecidos & & 1 & 0.9 & & & \\
\hline Desconhecidos & & 5 & 100 & & & \\
\hline \multicolumn{7}{|l|}{ Testudines } \\
\hline \multicolumn{7}{|l|}{ Geoemydidae } \\
\hline Rhinoclemmys punctularia & Aperema & 2 & 1.8 & LC & LC & $\mathrm{N} / \mathrm{C}$ \\
\hline Desconhecido & & 3 & 2.7 & & & \\
\hline DESCONHECIDO & & 5 & & & & \\
\hline Total & & 650 & & & & \\
\hline
\end{tabular}

Legenda: LC (pouco preocupante); N/C (não consta nas listas); VU(vulnerável).

Entre mamíferos silvestres, as ordens Didelphimorphia, Pilosa e Carnivora, juntos, somaram $79 \% \quad(n=139)$ dos mamíferos atropelados. A espécie Didelphis sp. (Figura. 4A) representou $27 \%(n=48)$ dos atropelamentos entre os mamíferos, seguida do Tamandua tetradactyla com $18 \%(n=31)$ e Cerdocyon thous com $16 \%$ $(n=28)$ dos registros. (Figura 4B, 4C). Entre as espécies de aves, as ordens Cathartiformes e Passeriformes somaram $78 \%(n=105)$ dos animais atropelados. A espécie Coragyps atratus (Figura 4D) foi a mais atropelada, com 55\% $(n=74)$ dos atropelamentos na rodovia, em seguida Crotophaga ani com $10 \%(n=14)$ dos atropelamentos. No grupo das espécies de répteis, a ordem Squamata representou 95\% $(n=104)$ dos atropelamentos, sendo que a família Boidae obteve $40 \%(n=44)$ dos registros, com destaque para espécie Boa constrictor (Figura 4E) que contabilizou $36 \%(n=39)$ de todos os répteis acidentados.

No grupo de anfíbios, a ordem Anura representou $100 \%(n=225)$ dos atropelamentos na rodovia, com principal representante da família Bufonidae com $64 \%(n=143)$ e Hylidae com $34 \%$ $(\mathrm{n}=77)$ dos atropelamentos. A espécie Rhinella marina (Figura 4F) foi a mais atropelada, com $58 \%(n=131)$ dos atropelamentos entre os anfíbios. 


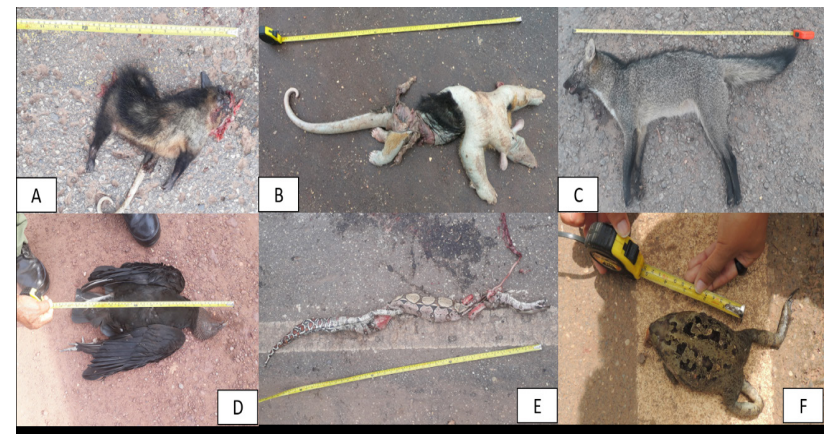

Figura 4 - Registros fotográficos das principais espécies atropeladas na BR-163, Oeste do Pará. (A) Didelphis marsupialis; (B) Tamandua tetradactyla; (C) Cerdocyon thous; (D) Coragyps atratus; (E) Boa constrictor; (F) Rhinella marina.

A taxa total de atropelamento observada foi de 0,08ind/km/dia, com uma média de 29 indivíduos encontrados atropelados por mês (Mín $=3$; Máx = 60). A maior taxa de atropelamento foi de anfíbios (0,03ind./km/dia), seguida de mamíferos (0,02ind./km/dia), aves (0,02ind./ $\mathrm{km} /$ dia) e répteis $(0,01 \mathrm{ind} . / \mathrm{km} / \mathrm{dia})$. Analisando as taxas de atropelamento por trechos, os anfíbios e mamíferos tiveram as mesmas taxas de atropelamento nos Trechos 2 e 3, enquanto no Trecho 1 os anfíbios obtiveram as maiores taxas. Já as aves tiveram o quádruplo da taxa de atropelamento no Trecho 1 em comparação aos Trecho 2 e 3, e os répteis foram mais atropelados nos Trechos 1 e 2 (Tabela 2).

Tabela 2 - Taxa de atropelamentos dos grupos de fauna registrados na BR-163, Pará.

\begin{tabular}{|c|c|c|c|}
$\begin{array}{c}\text { Taxa } \\
\text { total por } \\
\text { trecho }\end{array}$ & $\begin{array}{c}\text { Trecho } \mathbf{1}= \\
\mathbf{5 0} \mathbf{~ k m} \\
\mathbf{0 . 1 4} \mathbf{i n d} / \mathbf{k m} / \\
\mathbf{d i a}\end{array}$ & $\begin{array}{c}\text { Trecho } \mathbf{2}=\mathbf{6 7} \\
\mathbf{k m} \\
\mathbf{0 . 0 8 i n d} / \mathbf{k m} / \\
\mathbf{d i a}\end{array}$ & $\begin{array}{c}\text { Trecho } \mathbf{3}= \\
\mathbf{8 4} \mathbf{~ k m} \\
\mathbf{0 . 0 6} \mathbf{i n d} / \mathbf{k m} / \\
\mathbf{d i a}\end{array}$ \\
\hline $\begin{array}{c}\text { Mamífe- } \\
\text { ros }\end{array}$ & $0.03 \mathrm{ind} / \mathrm{km} / \mathrm{dia}$ & $0.03 \mathrm{ind} / \mathrm{km} / \mathrm{dia}$ & $0.02 \mathrm{ind} / \mathrm{km} / \mathrm{dia}$ \\
\hline Aves & $0.04 \mathrm{ind} / \mathrm{km} / \mathrm{dia}$ & $0.01 \mathrm{ind} / \mathrm{km} / \mathrm{dia}$ & $0.01 \mathrm{ind} / \mathrm{km} / \mathrm{dia}$ \\
\hline Anfíbios & $0.05 \mathrm{ind} / \mathrm{km} / \mathrm{dia}$ & $0.03 \mathrm{ind} / \mathrm{km} / \mathrm{dia}$ & $0.02 \mathrm{ind} / \mathrm{km} / \mathrm{dia}$ \\
\hline Répteis & $0.02 \mathrm{ind} / \mathrm{km} / \mathrm{dia}$ & $0.02 \mathrm{ind} / \mathrm{km} / \mathrm{dia}$ & $0.01 \mathrm{ind} / \mathrm{km} / \mathrm{dia}$ \\
\hline
\end{tabular}

Não encontramos relação entre as variáveis climáticas (precipitação total, temperatura máxima e mínima) e as taxas de atropelamento mensal para aves, anfíbios e répteis. Já para mamíferos, a taxa mensal de atropelamento foi maior com o aumento da temperatura e com a redução da precipitação (Tabela 3 e Figura 5).
Tabela 3 - Correlação dos atropelamentos com as variáveis climáticas, em negrito os valores significativos

\begin{tabular}{|c|c|c|c|c|}
\hline & $\begin{array}{l}\text { Mamíferos } \\
\text { (Sperman) }\end{array}$ & $\begin{array}{c}\text { Aves } \\
\text { (Pearson) }\end{array}$ & $\begin{array}{l}\text { Répteis } \\
\text { (Sperman) }\end{array}$ & $\begin{array}{l}\text { Anfíbios } \\
\text { (Sperman) }\end{array}$ \\
\hline $\begin{array}{l}\text { Precipitação } \\
\text { total }\end{array}$ & $\begin{array}{l}r s=-0.556 \\
(p)=0.016\end{array}$ & $\begin{array}{c}r=-0.233 \\
(p)=0.351\end{array}$ & $\begin{array}{l}r s=0.346 \\
(p)=0.159\end{array}$ & $\begin{array}{l}r s=-0.157 \\
(p)=0.533\end{array}$ \\
\hline $\begin{array}{l}\text { Temperatura } \\
\text { máxima }\end{array}$ & $\begin{array}{l}r s=0.584 \\
(p)=0.010\end{array}$ & $\begin{array}{c}r=0.014 \\
(p)=0.953\end{array}$ & $\begin{array}{l}r s=-0.231 \\
(p)=0.355\end{array}$ & $\begin{array}{l}r s=-0.078 \\
(p)=0.756\end{array}$ \\
\hline $\begin{array}{l}\text { Temperatura } \\
\text { mínima }\end{array}$ & $\begin{array}{l}r s=0.578 \\
(p)=0.011\end{array}$ & $\begin{array}{c}r=-0.118 \\
(p)=0.639\end{array}$ & $\begin{array}{l}r s=-.0359 \\
(p)=0.142\end{array}$ & $\begin{array}{l}r s=-0.153 \\
(p)=0.542\end{array}$ \\
\hline
\end{tabular}
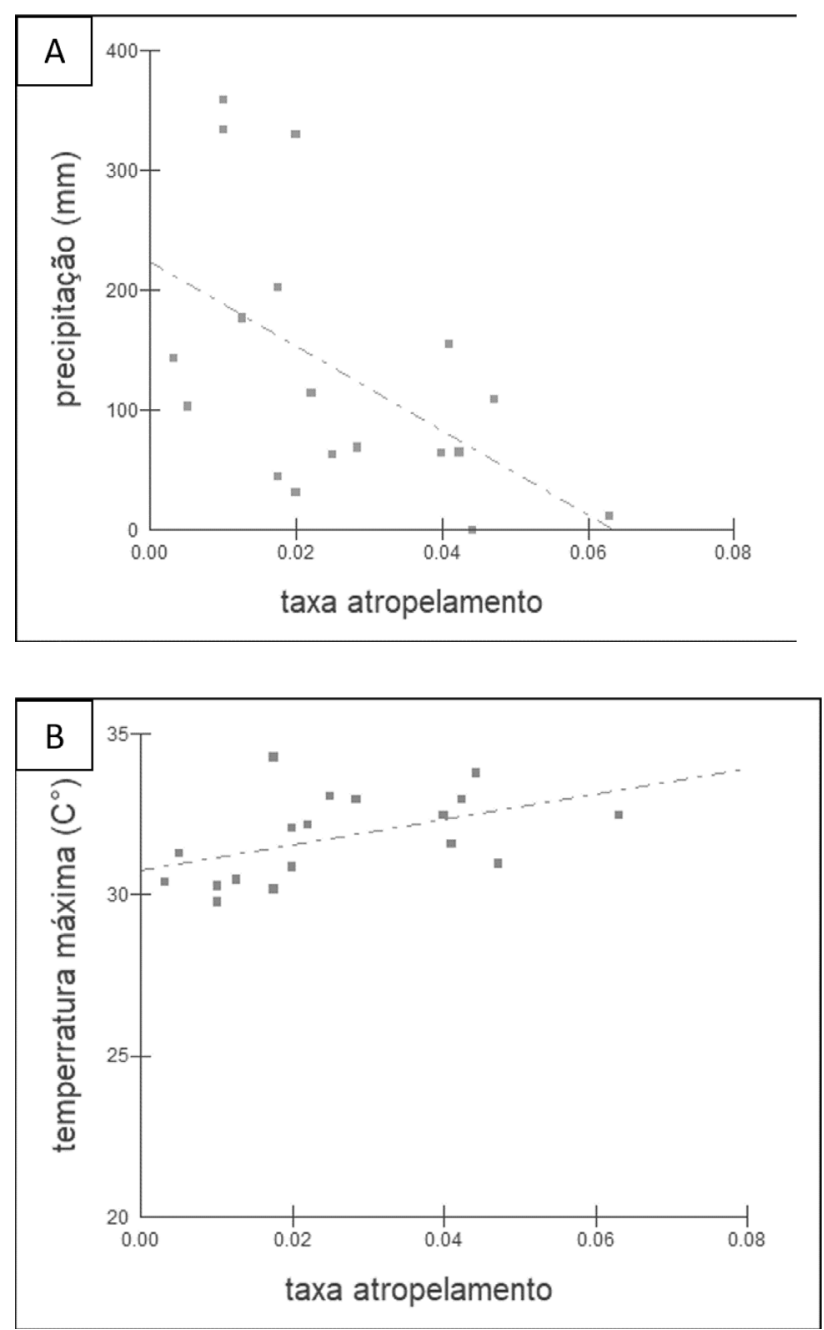

Figura 5 - A) relação da precipitação total e taxa de atropelamento de mamíferos. B) relação da temperatura máxima com taxa atropelamento mamíferos.

\section{Hotspots de atropelamento de fauna}

As maiores agregações de atropelamentos de mamíferos ocorreram, principalmente, nos Trecho 1 e 2. Encontramos pontos com alta densidade de atropelamentos (representados pela cor vermelho escuro), sendo os segmentos no Trecho 1, entre Mojuí dos Campos e o trevo de Belterra, houve uma agregação de mortalidade 
de Didelphis sp. $(\mathrm{N}=18)$, Tamandua tetradactyla $(\mathrm{N}=4)$, Cerdocyon thous $(\mathrm{N}=2)$. Já no Trecho 2 , o maior segmento de intensa mortalidade entre km 75 e 88, teve agregação de, principalmente, mortalidade de Didelphis sp. ( $\mathrm{N}=5)$, Cerdocyon thous $(\mathrm{N}=4)$, Tamandua tetradactyla $(\mathrm{N}=5)$. No Trecho 3, o maior segmento de intensidade atropelamento entre $\mathrm{km} 165$ a 179, foram de Didelphis sp. $(\mathrm{N}=2)$, Cerdocyon thous $(\mathrm{N}=2)$, Dasypus spp. $(\mathrm{N}=2)$ Hydrochoerus hydrochaeris $(\mathrm{N}=1)$, Nasua nasua $(\mathrm{N}=1)$, Mico argentatus $(\mathrm{N}=1)$ (Figura 6).

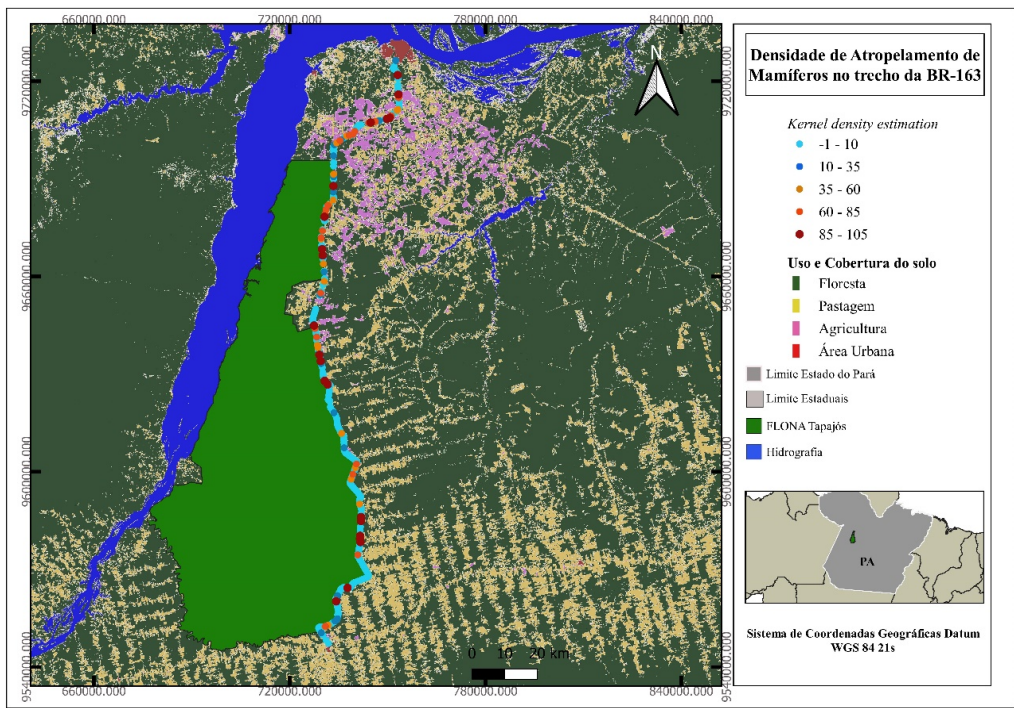

Figura 6 - Densidade de atropelamento de mamíferos na BR-163, entorno da Floresta Nacional do Tapajós, segmentos de alta densidade de atropelamento (manchas vermelhas). Fonte: Uso e cobertura do solo do MapBiomas.

Para aves, encontramos um segmento de alta densidade no Trecho 1 entre $\mathrm{km} 15$ ao 40, onde houve grande agregação de atropelamento de Coragyps atratus $(\mathrm{N}=34)$, ordem Passeriformes $(\mathrm{N}=7)$ e Crotophaga ani $(\mathrm{N}=4)$. E no trecho 3 com um segmento de forte intensidade de atropelamento, no km 180 a 190, foi, principalmente, de $\mid(\mathrm{N}=5)$ (Figura 7).

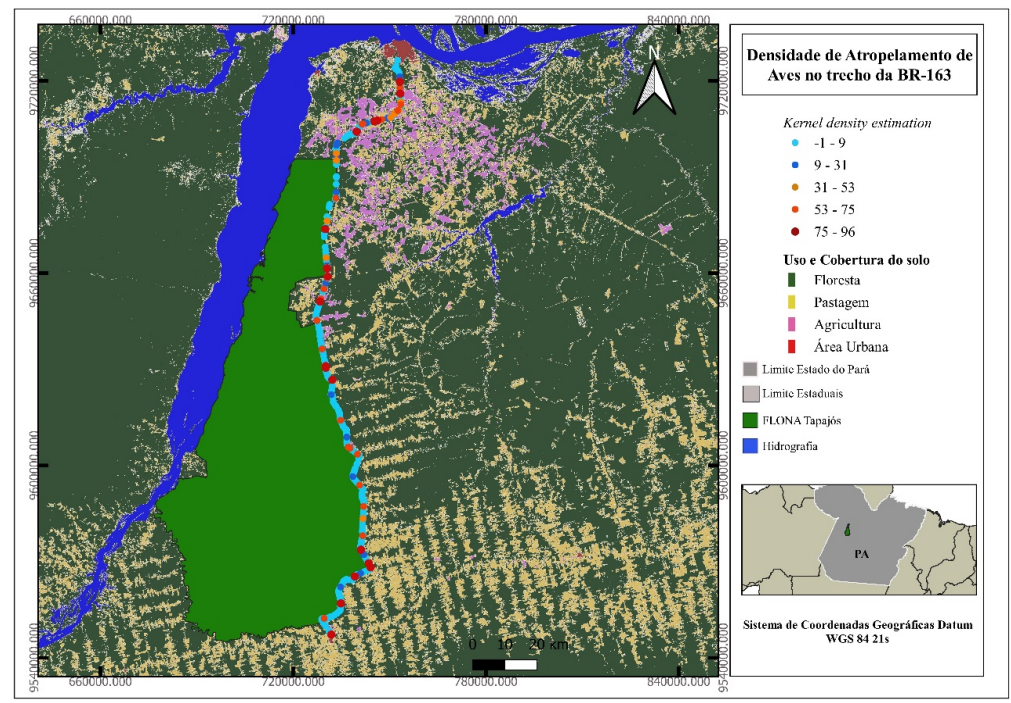

Figura 7 - Densidade de atropelamento de aves na BR-163, entorno da Floresta Nacional do Tapajós, e os segmentos de alta densidade de atropelamento (manchas vermelhas). Fonte: Uso e cobertura do solo do MapBiomas. 
A maior densidade de atropelamento para répteis foi nos Trechos 1 e 2 , resultando em dois segmentos de maior agregação de atropelamento. $\mathrm{O}$ primeiro segmento, no Trecho 1, entre $\mathrm{km} 30 \mathrm{a}$ 40, houve mortalidade da espécie Boa constrictor $(\mathrm{N}=11)$, Oxyrhopus petolarius $(\mathrm{N}=2)$, Philodryas olfersii $(\mathrm{N}=1)$ e Iguana iguana $(\mathrm{N}=1)$. O segundo segmento, no Trecho 2 , entre $\mathrm{km} 67$ a 84, teve o atropelamento de, principalmente, Boa constrictor $(\mathrm{N}=39), \quad$ Amphisbaena fuliginosa $(\mathrm{N}=8)$, Philodryas olfersii $(\mathrm{N}=5)$, Epicrates cenchria $(\mathrm{N}=4)$ e Ameiva ameiva $(\mathrm{N}=4)$ (Figura 8).

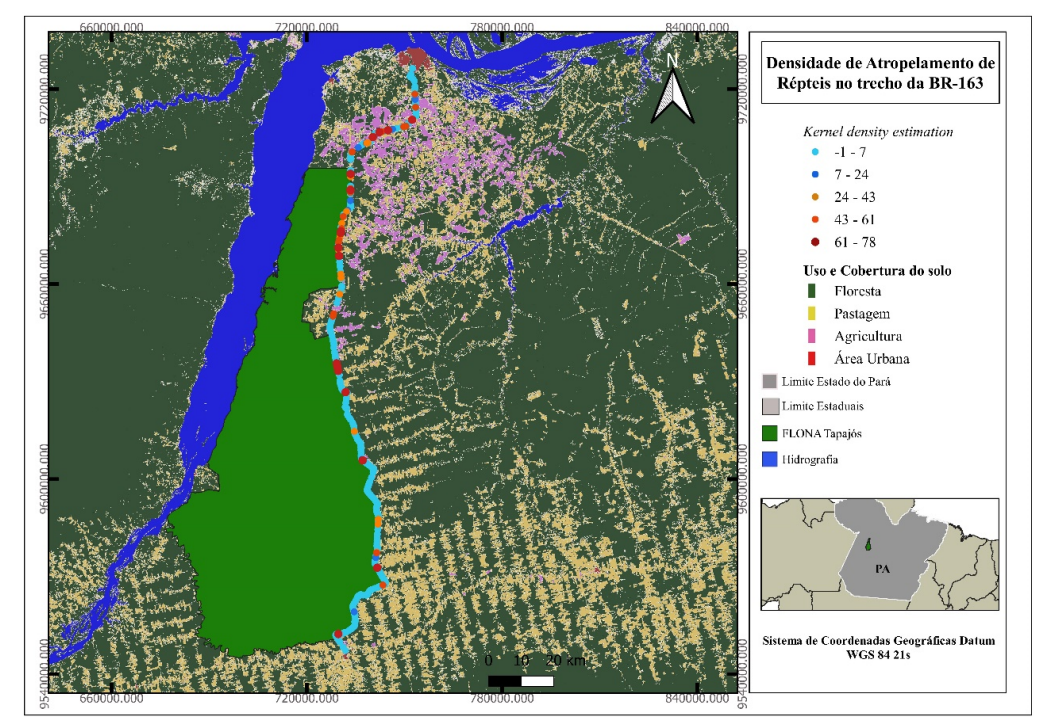

Figura 8 - Densidade de atropelamento de répteis na BR-163, entorno da Floresta Nacional do Tapajós, e os dois segmentos de alta densidade de atropelamento (manchas vermelhas). Fonte: Uso e cobertura do solo do MapBiomas.

Já os anfíbios tiveram alguns segmentos de altas densidades de atropelamento, em cada trecho darodovia. Osegmento do km 15 noTrecho 1 possui somente 200 metros, onde ocorreu agregação de mortalidade de espécies da família Hylidae $(\mathrm{N}=71)$. Importante destacar que os hilídeos foram majoritariamente atropelados nos meses de julho a setembro e tiveram $34 \%$ dos atropelamentos dessa família. Os segmentos próximos e do início da Flona Tapajós nos Trechos 1 e 2, os segmentos entre o km 100 ao 117, e o segmento de alta intensidade de atropelamento no Trecho 3, foram, principalmente, da espécie Rhinella marina $(\mathrm{N}=11$, $\mathrm{N}=18$ e $\mathrm{N}=16$, respectivamente) (Figura 9).

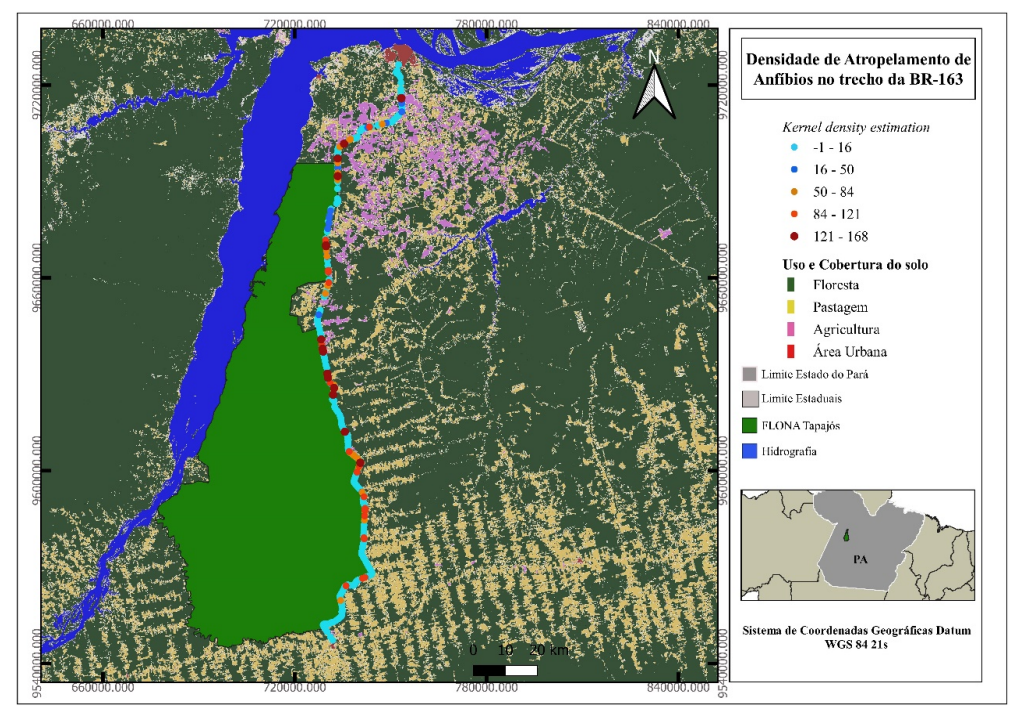

Figura 9 - Densidade de atropelamento de anfíbios na BR-163, entorno da Floresta Nacional do Tapajós, e os três segmentos de alta densidade de atropelamento (manchas vermelhas). Fonte: Uso e cobertura do solo do MapBiomas. 


\section{Discussão}

Apesar da Flona Tapajós ter uma extensão maior de rodovia (Trechos 2 e 3), o Trecho 1 apresentou maior taxa de atropelamento, que está relacionada a maiores registros das espécies de mamíferos (sobretudo Didelphis $\mathrm{sp}$ ), aves (sobretudo Coragyps atratus) e anfíbios (Hylidae). Nossos resultados mostram que somente o atropelamento de mamíferos foi influenciado pelas variáveis climáticas e que as principais agregações de atropelamento de fauna ocorreram sobretudo no Trecho 1 da nossa área de estudo, sendo o trecho associado a maior presença de aglomerações urbanas, e visivelmente, maior fluxo de veículos.

Apesar de nossos esforços para realizar o monitoramento em $201 \mathrm{~km}$ da BR-163, reconhecemos que existem possíveis equívocos na tentativa de estimar o número total de atropelamento e de determinar os fatores que influenciam a frequência do atropelamento. Nossas estimativas de taxa de atropelamento (ind./km/dia) provavelmente estão subestimadas, pois não foram consideradas a degradação da carcaça, detecção do observador e as taxas de remoção. Além disso, devido a extensão do trecho estudado, a detecção de carcaças nos trechos finais pode ser comprometida pela remoção da carcaça (Rosa et al., 2012; Barrientos et al., 2018). Da mesma forma, como não tínhamos acesso aos dados atualizados sobre a densidade do tráfego dos diferentes trechos, não conseguimos incluí-lo em nossas análises, contudo, durante os dois anos de monitoramento, foi visível notar diferença do maior fluxo de veículos no Trecho 1 e os Trechos 2 e 3 com fluxo mais baixo.

A contrário do comumente encontrado em alguns estudos com rodovias que cortam unidades de conservação no Brasil, de diferentes biomas, $e$ que realizam o monitoramento de fauna utilizando carro (Costa \& Sperber, 2009; Rodofauna, 2012; Martin, 2015), o grupo mais observado no nosso estudo foi os anfíbios. Apesar das altas taxas de atropelamento de anfíbios que encontramos no nosso estudo, sabemos que esses valores são ainda subestimados, devido à baixa detecção de anfíbios quando se utiliza veículos para amostragem de atropelamentos (Rosa et al., 2012) e rápida remoção da carcaça da pista (menos de 24 horas) devido ao pequeno porte das mesmas (Ratton et al., 2014).
O alto índice de atropelamento de anfíbios em nossa região de estudo deveu-se sobretudo a um evento específico de atropelamento, que ocasionou o registro, em uma única amostragem, de 71 anfíbios, especificamente da família Hylidae, em um trecho de 200 metros no $\mathrm{km} \mathrm{15}$, em dias com baixos índices de precipitação acumulado na semana nos meses mais quentes da região, diferentemente de alguns estudos que relatam a forte relação dos atropelamentos de anfíbios na pluviosidade (Coelho et al., 2012; Garriga et al., 2012).

O trecho do $\mathrm{km} 15$ possui presenças de poças permanentes e temporárias no entorno imediato da rodovia, que podem ter influenciado o evento único de atropelamento em massa desse grupo de anfíbios. Segundo Cunnington et al. (2014), a presença de poças temporárias formadas ao lado das estradas atrai esses animais para a proximidade das rodovias $e$, com seu comportamento reprodutivo e baixa mobilidade, há um aumento do risco de atropelamentos. Becker et al. (2007) ressaltam que a mudança de uso do solo tem frequentemente resultado em uma separação espacial do habitat de algumas espécies de anfíbios que, na fase de girinos e adultos, ocupam habitat diferentes, em muitos casos, forçando a travessia de estradas ou rodovias, na procura de corpos d'água ou remanescentes florestais.

Em relação aos mamíferos, estudos de Turci et al. (2009) e Medeiros (2019) apresentaram resultados similares ao nosso, com o aumento no número de mamíferos atropelados em meses mais secos na Amazônia. Esse fato pode estar relacionado à escassez de alimentos $e$ de água nesse período, forçando os animais a se deslocarem mais na paisagem e, portanto, ficando mais susceptíveis ao atropelamento (Loretto \& Vieira, 2005). Outro fator, segundo Aragão et al. (2007), é que a estação seca está relacionada com uma maior intensidade dos incêndios florestais na Amazônia, e os animais com maior mobilidade, como os mamíferos, conseguem se dispersar para longe dos incêndios (Frizzo et al., 2011), causando atropelamento quando tentam atravessar rodovias (Koproski, 2005).

Em relação às espécies mais atropeladas, nosso trabalho seguiu o padrão encontrado em outro estudo realizado no Pará (Pereira et al., 2006), em outros biomas do Brasil, que também relatam Didelphis sp, Cerdocyon thous e Tamandua 
tetradactyla, como os mamíferos mais atropelados (Cirino \& Freitas, 2018). O marsupial Didelphis sp., devido aos hábitos oportunistas, tem grande capacidade de adaptação ao meio urbano (Leiva, 2010), fato que pode estar relacionado a uma maior quantidade de atropelamentos no Trecho 1. Segundo Junior (2013), o Cerdocyon thous possui hábitos generalistas e se desloca bastante pelas paisagens, tornando-o mais suscetível ao atropelamento. Já a espécie Tamandua tetradactyla, possui hábitos noturnos, visão e audição limitadas, com movimentos lentos, aumenta o risco de atropelamento da espécie (Reis et al., 2010; Brum et al., 2017). Myrmecophaga tridactyla, ameaçado de extinção, foi encontrado no entorno da Flona Tapajós, em paisagem com influência da agricultura e floresta. Segundo Miranda et al. (2014), essa espécie ocorre em todos os biomas brasileiros em habitat como floresta densa e campos abertos, apesar de ter havido um único registro da espécie no trecho da pesquisa, Myrmecophaga tridactyla são eventualmente encontrados atropelados nas rodovias do Cerrado (Prado et al., 2006; Melo \& Santos-Filho, 2007 e Cáceres et al., 2012).

Entre os répteis, detacou-se o atropelamento de serpentes, animais que costumam utilizar rodovias e estradas para regulação térmica (Sullivan, 1981). Esse comportamento, facilita o atropelamento intencional, em muitos casos, tornando a rodovia uma armadilha ecológica para esses animais, inclusive resultando em atropelamentos intencionais (Secco et al., 2014; Mccardle \& Fontenot, 2016). Entre as espécies mais atropeladas, destacamos a Boa constrictor, predominante em ambientes antropizados (Trecho 1), assim como encontrado em outros estudos na Amazônia (Turci \& Bernarde, 2009) e Cerrado (Carvalho, 2014). As características generalistas do uso de habitat e da dieta da B. constrictor facilitam a expansão para ambientes alterados, com destaque para ambientes com resíduos sólidos acumulados, que atraem roedores e podem manter populações maiores de serpentes em áreas urbanas (Bernarde \& Abe, 2006; Pizzatto et al., 2009; Barbo et al., 2011).

Também no Trecho 1, destacou-se o atropelamento de Coragyps atratus, o que é esperado, visto que aves necrófagas diurnas habitam frequentementeáreas próximas a rodovias, aproveitando a alta disponibilidade de carcaças e de lixo urbano (Slater, 2002; Cardoso, 2010).
Já Crotophaga ani, outra espécie de ave muito atropelada no nosso estudo, torna-se suscetível aos atropelamentos devido habitar áreas de borda e ao comportamento de realizar voos rasantes nas proximidades da estrada ou, mesmo, por se alimentar de grãos disponíveis na rodovia e seu entorno (Clevenger et al., 2003; Prada, 2004; Laurance et al., 2004).

Os hotspots de atropelamento por classe demonstram densidade agrupada em várias espécies, o que pode ser considerado uma oportunidade de instalação de medidas de mitigação comum, quando as espécies e hotspots são semelhantes (Texeira et al., 2013). Contudo, recomendam-se análises de hotspots para espécies-específicas ou de interesse, principalmente se o estudo for avaliar medidas de mitigação (Lesbarrères \& Fahrig, 2012). Nossos resultados podem ser utilizados como indicativos de trechos com potencial necessidade de medidas de mitigação na BR-163. As passagens de fauna com cercas direcionadoras são medidas muito eficientes para reduzir o atropelamento e manter o fluxo gênico entre as populações (Rytwinski et al., 2016; Huijser et al., 2016; Helldin \& Petrovan, 2019; Jarvis et al., 2019; Cordeiro, 2019; Abra et al., 2020).

O aumento dos movimentos entre as populações divididas por estradas pode afetar positivamente, por exemplo, o sucesso da dispersão ou o acesso a parceiros reprodutivos (ver, por exemplo, Mansergh e Scotts, 1989) e, consequentemente, a dinâmica populacional das espécies que vivem no entorno de rodovias. Porém, no Brasil, em rodovias já construídas e sem planejamento de ampliação a curto prazo, uma medida como essa se torna inviável do ponto de vista político e econômico. Sendo assim, outras medidas simples e de baixo custo podem ser instaladas sem necessidade de grandes projetos de engenharia, como é o caso da redutores de velocidade e cercas no entorno da rodovia, sobretudo nos hotspots de atropelamento no entorno da Flona Tapajós. As cercas podem, inclusive, ser construídas de forma a direcionar os animais para bueiros ou canais de drenagem da rodovia, proporcionam uma travessia segura para muitas espécies, incluindo espécies de médio e grande porte (Ascensão \& Mira, 2007; Banhos et al., 2020; Abra et al., 2020). Todavia existe necessidade de planejamento, monitoramento $e$ manutenção dessas medidas, visando ao aumento 
da sua efetividade (Forman et al., 2003; Rytwinski et al., 2016; Teixeira et al., 2020) e não efeito oposto do esperado (Mata et al., 2008). Além de medidas diretas nas rodovias, a melhora no gerenciamento de resíduos sólidos, com campanhas educativas nas comunidades do entorno da rodovia, abordando temas como segregação $e$ acondicionamento do lixo doméstico, e a instalação de container grandes e fechados para armazenamento desses resíduos, podem reduzir drasticamente a atração e consequente risco de atropelamento de animais sinantrópicos (Dyson \& Chang, 2005), além de melhorar a qualidade de vida e saúde pública das pessoas que vivem nessa região.

Finalmente, segundo o PRIM-IVT (Plano de Redução de Impacto de Infraestruturas Viárias Terrestres sobre a Biodiversidade do ICMBio), cabe destacar que a BR-163 é a via com maior extensão de trechos presentes em áreas de muito baixa compatibilidade com a conservação da biodiversidade e alta sensibilidade da biodiversidade na resistência e resiliência aos impactos das infraestruturas viárias terrestres. Recomenda- se, então, para construção de novas vias que essas áreas sejam evitadas (PRIM,2018), principalmente áreas que cortam unidades de conservação que são refúgios para muitas espécies ameaçadas e raras. Se, por um lado, a Flona Tapajós é um refúgio para fauna, por outro lado ,pode indicar que a rodovia está causando outros efeitos, como o efeito de borda e efeito barreira (Ascensão \& Mira 2007; Rosa et al., 2018;), impactos esses que devem ser melhor investigados em futuros trabalhos.

\section{Conclusão}

Nossos resultados mostram que, apesar da alta diversidade da Flona Tapajós, poucas espécies ameaçadas de extinção foram registradas atropeladas. Pode ser um indicativo de que o baixo fluxo de veículos e as áreas de conservação da Flona Tapajós contribuíram para menos registros de animais atropelados. Identificamos a dominância de algumas espécies nos atropelamentos, como Didelphis sp, Cerdocyon thous, Tamandua tetradactyla, Boa constrictor e Rhinella marina, corroborando com estudos em outras regiões do Brasil. Apesar de ser espécies comuns, cumprem diferentes funções ecológicas nos ecossistemas, às vezes até mais significativos do que espécies raras $e$ ameaçadas, já que estão em baixa densidade.
Além disso, as espécies comuns não necessitam de um esforço amostral grande como as espécies raras para escolha de trechos prioritários visando a construção de medidas de mitigação.

As altas densidades de atropelamentos (hotspots) estão aparentemente relacionadas aos hábitos dos animais e a paisagem do entorno, com alto índice de animais sinantrópicos sendo atropelados em trechos mais próximos a centros urbanos. Especificamente os anfíbios apresentaram altas taxas de atropelamento, embora nosso método (uso de veículo a $50 \mathrm{~km} / \mathrm{h}$ ) não seja o mais adequado para amostragem desse grupo. O grupo dos mamíferos foi o único que sofreu influência das variáveis climáticas, cuja taxa de atropelamento foi maior em períodos mais quentes e secos, podendo ser um reflexo da distribuição dos recursos na paisagem, ou mesmo da alta incidência de focos de incêndios florestais na região nesses períodos.

Os resultados desta pesquisajunto com dados do Plano de Redução de Impacto de Infraestruturas Viárias Terrestres sobre a Biodiversidade do ICMBio mostram os impactos da Rodovia BR-163 para a fauna silvestre da Amazônia, servindo de subsídio para o planejamento $e$ concessão de outras rodovias dessa região.

\section{Agracedimentos}

Agradecemos aos gestores e funcionários da Floresta Nacional do Tapajós e do ICMBio Regional Santarém pelo apoio com a logística do projeto, e a bolsa de iniciação científica do Programa Institucional de Bolsas de Iniciação Científica do Instituto Chico Mendes de Conservação da Biodiversidade(PIBIC/ICMBio).

\section{Referências}

Abra FD, Huijserd MP, Magiolia M, Bovo AAA \& Ferraza KMPMB. An estimate of wild mammal roadkill in São Paulo state, Brazil. Available online, 2021.

Abra F, Canena AC, Garbino GST \& Medici EP. Use of unfenced highway underpasses by lowland tapirs and other medium and large mammals in central-western Brazil. Perspectives in Ecology and Conservation, v. 18, p. 247-256, 2020.

Alencar AAC. A rodovia $\mathrm{Br}-163$ e o desafio da sustentabilidade - Relatório do Projeto. MAPAS, 2005. 
Aragão L et al. Spatial patterns and fire response of recent Amazonian droughts. Geophysical Research Letters, 2007.

Ascensão F \& Mira A. Factors affecting culvert use by vertebrates along two stretches of road in southern Portugal. Ecological Research,22: 57-66, 2007.

Ayres M, Ayres-jr M \& Santos AS. BioEstat 3.0. Aplicações Estatísticas nas áreas das Ciências BioMédicas. Sociedade Civil Mamirauá, 290Pp. 2007.

Bager A \& Rosa CA. Priority ranking of road sites for mitigating wildlife roadkill.Biota Neotropica, v. 10, n. 4, 2010.

Banhos A, Fontes BL, Yogui DR, Alves MH, Ardente NC \& Valls R, Schettino VR. Highways are a threat for giant armadillos that underpasses can mitigate. Biotropica, 2020.

Barbo FE, Marques OAV \& Sawaya RJ. Diversity, Natural History, and Distribution of Snakes in the Municipality of São Paulo. South American Journal of Herpetology, 6(3): 135-160, 2011.

Braz VS \&, França FGR. Wild vertebrate roadkill in the Chapada dos Veadeiros National Park, Central Brazil. Biota Neotropica, 16:1-11, 2016.

Becker CG, Fonseca CR, Haddad CFB, Batista RF \& Prado PI. Habitat-split and the Global Decline of Amphibians. Science, v. 318, 2007.

Bernarde OS \& Abe AS. A snake community at Espigão do Oeste, Rondônia, southwestern Amazon, Brazil. South American Journal of Herpetology, 1(2): 102-11,2006.

BRASIL. Ministério do Planejamento, Orçamento e Gestão. Plano de desenvolvimento sustentável para a região de influência da rodovia br-163 (PLANO CUIABÁ-SANTARÉM SUSTENTÁVEL). Brasillia, 2004.

Brum TR, Santos-Filho M, Canales GR \& Ignacio RA. Effects of roads on the vertebrates diversity of the Indigenous Territory Paresi and its surrounding. Brazilian Journal of Biology, 78(1):125-132,2017.

Câmara G \& Carvalho MS. Análise de eventos pontuais. In: druck, s.; Carvalho M.S., Câmara G, Monteiro, AVM. Análise espacial de dados geográficos. Brasília, EMBRAPA, 2004.

Carvalho CF. Atropelamento de vertebrados, hotspots de atropelamento e parâmetros associados, BR-050, trecho Uberlândia-Uberaba. (Mestrado em Ecologia). Universidade Federal de Uberlândia, 2014.

Cardoso TR. Tempo de permanência de carcaças em rodovias: análise metodológica em ecologia de estradas. Undergraduate thesis. Universidade Federal de Lavras, 2010.
Carneiro EO \& Santos RL. Análise espacial aplicada na determinação de áreas de risco para algumas doenças endêmicas (calazar, dengue, diarréia, DST - Doenças sexualmente transmissíveis e tuberculose), no bairro de Campo Limpo, Feira de Santana (BA). Sitientibus, v.28, p. 51-75, 2003.

Cáceres N, Casella J \& Santos Goulart C. Variação espacial e sazonal de atropelamentos de mamíferos no bioma Cerrado, rodovia BR 262, sudoeste do Brasil. Mastozoología Neotropical, 19(1): 21-33, Mendoza, 2012.

CBEE (Centro Brasileiro de Estudos em Ecologia de Estradas). Projeto Malha Manual para Equipe de Campo, 2013.

Chainey S, Tompson, L \& Uhlig, S. The utility of hotspot mapping for predicting spatial patterns of crime. Security journal, Springer, v. 21, n. 1-2, p. 4-28, 2008.

Cirino DW \& Freitas SR. Quais são os mamíferos silvestres mais atropelados no Brasil? p.48-56. In: Anais do $5^{\circ}$ Workshop de Evolução e Diversidade, 2018.

Clevenger AP, Chruszcz B \& Gunson KE. Spatial patterns and factors influencing small vertebrate fauna road-kill aggregations. Biological conservation, 109(1): 15-26, 2003.

Coelho IP, Kindel A \& Coelho AVP. Roadkills of vertebrate species on two higways through the Atlantic Forest Biosphere Reserve, southern Brazil. Eur. J. Wildl, 2008.

Coelho, IP, Teixeira, FZ, Colombo P, Coelho A VP \& Kindel, A. Anuran road-kills neighboring a periurban reserve in the Atlantic Forest, Brazil. Journal of environmental management, 112, 17-26, 2012.

Costa FG \& Sperber CF. Atropelamentos de vertebrados na Floresta Nacional de Carajás, Pará, Brasil. Acta Amazonia, 39 (2), 2009.

Cordeiro JFA. Efeito mitigador das barreiras antiatopelamento de anfíbios na estrada municipal EM 529. Dissertação (Mestrado em Biologia da Conservação). Universidade de Évora. 51p.,2019.

Cunnington GM, Garrah E, Eberhardt E \& Fahrig L. Culverts alone do not reduce road mortality in anurans. Écoscience 21, 69-78, 2014.

Dornas RAP, Kindel A, Bager A \& Freitas SR. Avaliação da mortalidade de vertebrados em rodovias.In :BAER.A.(ed) Ecologia de Estradas: tendência e pesquisa. Lavras:Ed. UFLAp.139-152, 2012.

Druck S, Carvalho MS, Camara G \& Monteiro AMV. Análise espacial de dados geográficos. Cad. Saúde Pública vol.21 n.4, 2005. 
Dyson B \& Chang NB. Forecasting municipal solid waste generation in a fast-growing region with system dynamics modeling. Waste Management, 25(7); 669679, 2005.

ESRI. Classifying Numerical Fields for Graduated Symbology. Disponível em:

<http://desktop.arcgis.com/en/arcmap/10.3/map/ working-with-layers/classifying-numerical-fieldsforgraduated-symbols.htm > . Acesso em: 23/04/2021.

Fearnside PM \& Laurance WF. Infraestrutura na Amazônia: as lições dos planos plurianuais, Cad. $\mathrm{CRH}$ Scielo, vol. 25, 2012.

Fearnside PM. A tomada de decisão sobre grandes estradas amazônicas. pp. 59-75. In: A Bager (Ed.) Ecologia de Estradas: Tendências e Pesquisas. Universidade Federal de Lavras, 313p. 2012.

Forman RT \& Alexander LE. Roads and their major ecological effects. Ann. Rev. Ecol. Syst, 1998.

Forman RTT et al. Science and solutions. Island Press, Washington, DC, 2003.

Garriga N, Santos X, Montori A, Richter-Boix A, Franch M \& Llorente GA. Are protected areas truly protected? The impact of road traffic on vertebrate fauna. Biodiversity and Conservation, 21(11), 2761-2774, 2012.

Grilo C, Bissonette JA \& Santos-Reis, M. Spatialtemporal patterns in Mediterranean carnivore road casualtis: Consequences for mitigation. Biological Conservation. V. 142,p.301-313, 2009.

Gunson K \& Teixeira FZ. Road- Wildlife mitigation planning can be improved by identifying the patterns and processes associated with wildlife-vehicle collisions. In Ree R, Smith Dj \& Grilo O. (Orgs). 1. ed. Handbook of road ecology. West Sussex, UK: John Wiley \& Sons, p. 101-109, 2015.

Hegel CGZ, Consalter GC \& Zanella N. Mamíferos silvestres atropelados na rodovia RS - 135, norte do Estado do Rio Grande do Sul. Biotemas, 25(2): 165$170,2012$.

Frizzo TLM, Bonizario C, Borges MP \& Vasconcelos H. Revisão dos efeitos do fogo sobre a fauna de formação savânica do Brasil. Oecologia Australis 15(15):365$379,2011$.

Helldin JO \& Petrovan SO. Effectiveness of small road tunnels and fences in reducing amphibian roadkill and barrier effects; case studies of retrofitted roads in Sweden. PeerJ Preprints, 2019.
Huijser MP et al. Effectiveness of short sections of wildlife fencing and crossing structures along highways in reducing wildlife-vehicle collisions and providing safe crossing opportunities for large mammals. Biological Conservation, 197(61): 68, 2016.

IBAMA (Instituto Brasileiro do Meio Ambiente e dos Recursos Naturais Renováveis). Floresta Nacional do Tapajós. Plano de Manejo. Belterra: IBAMA, 373p. 2004.

ICMBio (Instituto Chico Mendes de Conservação da Biodiversidade). A Floresta Nacional do Tapajós. <http://www.icmbio.gov.br/flonatapajos/>. Acesso em: 21/04/ 2018.

ICMBio (Instituto Chico Mendes de Conservação da Biodiversidade). Livro Vermelho da Fauna Brasileira Ameaçada de Extinção: Volume I / 1. ed. - Brasília, DF: ICMBio/MMA, p. 492, 2018.

INMET (Instituto Nacional de Meteorologia). Dados meteorológicos. <http:/http://www.inmet.gov.br/ portal//>. Acesso em: 29/07/2019.

INPE (Instituto Nacional de Pesquisas Espaciais). Projeto TERRACLASS-2012 - Mapeamento do Uso e Cobertura da Terra na Amazônia Legal Brasileira, Brasília, 2014.

IBRAM (Instituto Brasília Ambiental). Relatório Rodofauna.21p.,2012.

Jackson ND \& Fahrig L. Relative effects of road mortality and decreased connectivity on population genetic diversity. Biol. Conserv. 144: 3143-3148,2011.

Jarvis LE, Hartup M \& Petrovan SO. Road mitigation using tunnels and fences promotes site connectivity and population expansion for a protected amphibian. Eur. J. Wildl.,2019.

Junior TSS. Mamíferos do Cerrado de Mato Grosso, com ênfase no uso de espaços por Cerdocyon thous (Carnivora, Canidae) e Mazama gouazoubira (Artyodctyla, Cervidae). Tese (Doutorado em Ecologia). Universidade Federal de São Carlos. 97p., 2013.

Koproski PL. O fogo e seus efeitos sobre a herpeto e a mastofauna terrestre no parque nacional de ilha grande (pr/ms), Brasil. Dissertação (Mestrado em Ciências Florestais). Universidade Federal do Paraná.143p.,2005.

Laurance WF, Goosem M \& Laurance SGW. Impacts of roads and linear clearings on tropical forests. Trends in Ecology and Evolution, 24(12): 659- 669,2009.

Laurance SGW, Stouffer PC \& Laurance WF. Effects of road clearings on movement patterns of understory rainforest birds in central Amazonia. Conservation Biology, volume 18, 2004. 
Leiva M. Frugivoria e germinação de sementes após passagem pelo sistema digestivo de marsupiais em florestas estacional semidecidual. Dissertação (Mestrado em Ciências Biológicas). Universidade Estadual Paulista. 53p. 2010.

Lesbarrères D \& Fahrig L. Measures to reduce population fragmentation by roads: what has worked and how do we know? Trends in ecology and evolution, 27: 374-380, 2012.

Loretto D \& Vieira MV. The effects of reproductive and climatic seasons on movements in the black-eared opossum (Didelphis aurita Wied Neuwied, 1826). Journal of Mammalogy, 86:287-293, 2005.

MacielS.Padrõesespaciaise temporais noatropelamento de vertebrados silvestres em duas Estradas - Parque no Cerrado do Brasil Central. Dissertação (Mestrado em Ciências Florestais). Universidade de Brasília.79p. 2019.

Martin CF. Monitoramento de fauna silvestre atropelada no entorno da Estação Ecológica de Carijós. Trabalho de Conclusão de Curso da Universidade Federal de Santa Catarina, 2005.

Mansergh IM \& Scotts DJ. Habitat continuity and social organization of the mountain pygmy-possum restored by tunnel. Journal of Wildlife Management 53:701707, 1989.

Mata, C et al. Are motorway wildlife passages worth building? Vertebrate use of road-crossing structures on a Spanish motorway. Journal of Environmental Management, v. 88, 407-415, 2008.

Medeiros ASM. Vertebrados atropelados na Amazônia: monitoramento em longo prazo, influência do fluxo de veículos e alternância de hotspots em um trecho da rodovia br-174, Brasil. (Mestrado em Ecologia) Instituto Nacional de Pesquisas da Amazônia. 49p. 2019.

Medici EP, Abra FD, Fernandes-Santos RC \& Testa-José C. Impacto de atropelamentos da fauna, particularmente anta brasileira, em rodovias estaduais e federais do estado de Mato Grosso do Sul, Brasil. Relatório Parcial da Iniciativa Nacional para a Conservação da Anta Brasileira (INCAB), Instituto de Pesquisas Ecológicas (IPE) 2016.

Melo ES \& Santos-Filho M. Efeitos da BR070 na Província Serrana de Cáceres, Mato Grosso, sobre a comunidade de vertebrados silvestres. Revista Brasileira de Zoociências, 9(2):185-192, 2007.

Mccardle LD \& Fontenot CL. The influence of thermal biology on road mortality risk in snakes. Journal of thermal biology, 56; 39-49,2016.
Miranda F, Bertassoni A \& Abba AM. Myrmecophaga tridactyla. The IUCN Red List of Threatened Species, 2014. Moraes BC, Costa JMN, Costa ACL, Costa MH. Variação espacial e temporal da precipitação no estado do Pará. Acta Amazonica, 35(2):207-214, 2005.

Prado TR, AA Ferreira \& ZFS Guimarães. Efeito da implantação de rodovias no cerrado brasileiro sobre a fauna de vertebrados. Acta Scientiarum, Biological Sciences 28(3): 237-241, 2006.

Pastre R. Plano de desenvolvimento regional BR-163 sustentável: Avaliação das repercussões das ações estratégicas em infraestrutura sobre o norte do Mato Grosso. Economia Regional, Urbana e do Trabalho,07 (01), 2018.

Pereira, APFG, Andrade FAG \& Fernandes MEB. Dois anos de monitoramento dos atropelamentos de mamíferos na rodovia PA-458, Bragança, Pará. Bol. Mus. Para. Emilio Goeldi Cienc. Nat. v.1 n.3,2006.

Prada CS. Atropelamento de vertebrados silvestres em uma região fragmentada do nordeste do Estado de São Paulo: quantificação do impacto e análise de fatores envolvidos. (Mestrado em Ecologia Universidade Federal de São Carlos. 129p. 2004.

Projeto MapBiomas - Coleção 5 da Série Anual de Mapas de Cobertura e Uso de Solo do Brasil. Acessado em (12/01/2020) através do link: www.mapbiomas.org.

Pinho GSC et al. Efeito de diferentes métodos de corte de cipós na produção de madeira em tora na Floresta Nacional do Tapajós. Revista Ciência Florestal, 14(1):179-192, 2004.

Pizzatto L, Marques OAV \& Facure K. Food habits of Brazilian boid snakes: overview and new data, with special reference to Corallus hortulanus. AmphibiaReptilia, 30(4): 533-544, 2009.

Pinto F, Clevenger AP \& Grilo C. Effects of roads on terrestrial vertebrate species in Latin America. Environmental Impact Assessment Review, 81(106337):1-8, 2020.

Ponte FC, Furtado AM, Silva CN, Silva JMP, Lima RS. Parâmetros fisiográficos e impactos ambientais da rodovia Santarém-Cuiabá (BR-163), estado do Pará (Brasil). PRODEMA Fortaleza, 9(2):53, 2015.

Ratton P, Secco H \& Rosa CA. Carcass permanency time and its implications to the roadkill data. European journal of wildlife research, 60(3): 543-546.2014.

Reis NR, Peracchi AL, Fregonezi MN \& Rossaneis BK. Mamíferos do Brasil - guia de identificação. Technical Books Editora,1ed, 577p. 2010.

Ricklefs RE. A economia da natureza. 6 ed. Guanabara Koogan. 546p. 2010. 
Rytwinski T, Soanes K, Jaeger JAG, Fahrig L, Findlay $\mathrm{CS}$, Houlahan J et al. How Effective Is Road Mitigation at Reducing Road-Kill? A Meta-Analysis. PLoS ONE, 2016.

Rosa CA, Cardoso TR, Teixeira FZ \& Bager A. Atropelamento de fauna selvagem: Amostragem $e$ análise de dados em ecologia de estradas. Ed. UFLA. In: Ecologia de estradas: tendências e pesquisas, 2012.

Rosa AO \& Maus J. Atropelamento de animais silvestres na rodovia RS-040. Caderno de Pesquisa Sér.Bio, 16:35-42, 2004.

Secco H, Ratton P, Castro E, Lucas PS \& Bager A. Intentional snake road-kill: a case study using fake snakes on a Brazilian road. Tropical Conservation Science, 7(3): 561-571, 2014.

SETRAN (Secretária do Estado de Transporte) Pesquisa Rodovias Estado do Pará . <httphttp://setran. pa.gov.br/site/>. Acesso em: 22/07/2020

Slater FM. An assessment of wildlife road casualtiesthe potential discrepancy between numbers counted and numbers killed. Web Ecol, 3: 33-42,2002.

Sullivan BK. Observed differences in body temperature and associated behaviour of four snake species. Journal of Herpetology, 15:245-246,1981.
Teixeira FZ et al. Are road-kill hotspots coincident among different vertebrate groups? Oecologia Australis 17:36-47.,2013.

Teixeira FZ, Gonçalves LO, Biasotto LD, Nóbrega RAA \& Kindel A. Ferramentas geográficas para análise e mitigação de impactos ambientais causados por infraestruturas viárias de transporte terrestre. In: Sutil T, Pereira JR, Ladwig NI, Zocche JJ, Pereira JL (org.). Geoprocessamento na análise ambiental. Criciúma (SC): Unesc, 2020.

Turci LCB \& Bernarde PS. Vertebrados atropelados na rodovia estadual 383 em Rondônia, Brasil. Biotemas, 22(1): 121-127, 2009.

Wenhao Y \& Tinghua A. The visualization and analysis of urban facility pois using network kernel density estimation constrained by multi-factors. Bol. Ciênc. Geod, vol. 20 n. 4, 2014.

Winton SA, Bishop CA \& Larsen KW. When protected areas are not enough: low-traffic roads projected to cause a decline in a northern viper population. Endang. Species Research, 41:131-139, 2020.

Zandonadi AP, Brunaldi FG, Meneguelli AZ \& Araújo RMG. Vertebrados atropelados na br-429 no eixo alvorada d' oeste-São Miguel do Guaporé, Rondônia, Brasil. Revista Científica da UNESC, 12(1), 2014.
Biodiversidade Brasileira - BioBrasil.
Edição Temática: PIBIC

n. 1,2022

http://www.icmbio.gov.br/revistaeletronica/index.php/BioBR

Biodiversidade Brasileira é uma publicação eletrônica científica do Instituto Chico Mendes de

Conservação da Biodiversidade (ICMBio) que tem como objetivo fomentar a discussão e a disseminação de experiências em conservação e manejo, com foco em unidades de conservação $e$ espécies ameaçadas. 